\title{
BMC
}

Evolutionary Biology

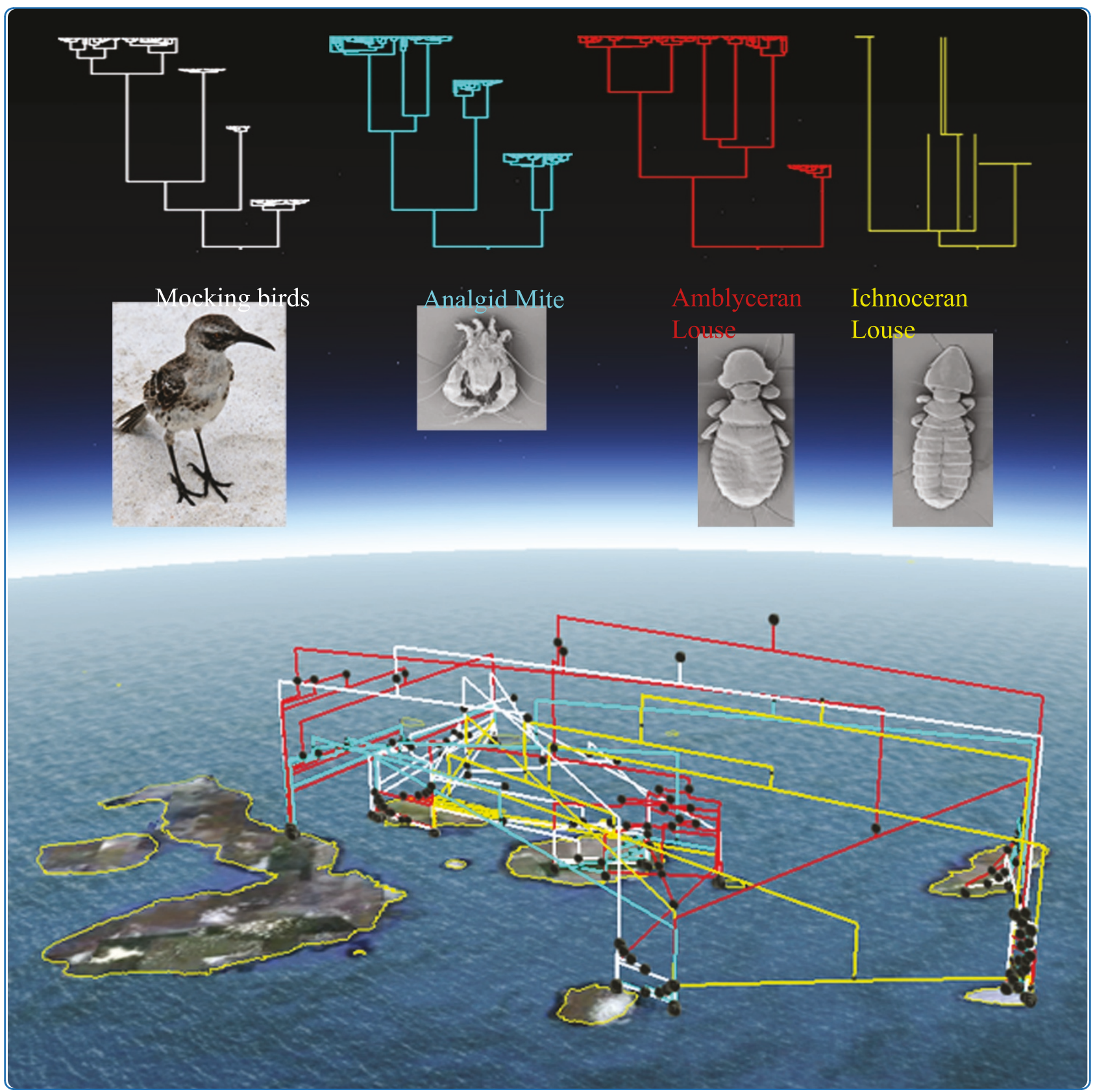

\section{A hitchhikers guide to the Galápagos: co-phylogeography of Galápagos mockingbirds and their parasites}

Štefka et al. 


\title{
A hitchhikers guide to the Galápagos: co- phylogeography of Galápagos mockingbirds and their parasites
}

\author{
Jan Štefka ${ }^{1,2^{*}}$, Paquita EA Hoeck ${ }^{3}$, Lukas F Keller ${ }^{3}$ and Vincent S Smith ${ }^{1}$
}

\begin{abstract}
Background: Parasites are evolutionary hitchhikers whose phylogenies often track the evolutionary history of their hosts. Incongruence in the evolutionary history of closely associated lineages can be explained through a variety of possible events including host switching and host independent speciation. However, in recently diverged lineages stochastic population processes, such as retention of ancestral polymorphism or secondary contact, can also explain discordant genealogies, even in fully co-speciating taxa. The relatively simple biogeographic arrangement of the Galápagos archipelago, compared with mainland biomes, provides a framework to identify stochastic and evolutionary informative components of genealogic data in these recently diverged organisms.

Results: Mitochondrial DNA sequences were obtained for four species of Galápagos mockingbirds and three sympatric species of ectoparasites - two louse and one mite species. These data were complemented with nuclear EF1 $\alpha$ sequences in selected samples of parasites and with information from microsatellite loci in the mockingbirds. Mitochondrial sequence data revealed differences in population genetic diversity between all taxa and varying degrees of topological congruence between host and parasite lineages. A very low level of genetic variability and lack of congruence was found in one of the louse parasites, which was excluded from subsequent joint analysis of mitochondrial data. The reconciled multi-species tree obtained from the analysis is congruent with both the nuclear data and the geological history of the islands.

Conclusions: The gene genealogies of Galápagos mockingbirds and two of their ectoparasites show strong phylogeographic correlations, with instances of incongruence mostly explained by ancestral genetic polymorphism. A third parasite genealogy shows low levels of genetic diversity and little evidence of co-phylogeny with their hosts. These differences can mostly be explained by variation in life-history characteristics, primarily host specificity and dispersal capabilities. We show that pooling genetic data from organisms living in close ecological association reveals a more accurate phylogeographic history for these taxa. Our results have implications for the conservation and taxonomy of Galápagos mockingbirds and their parasites.
\end{abstract}

\section{Background}

Parasites represent evolutionary hitchhikers on their hosts with evolutionary histories of each lineage often running in parallel [e.g. [1,2]]. When the hosts speciate, those parasites which are host specific may also become reproductively isolated, potentially leading to co-speciation. Analysis of these host-parasite associations is analogous to reconstructing the evolution of genes tracking

\footnotetext{
* Correspondence: jan.stefka@gmail.com

${ }^{1}$ Entomology Department, Natural History Museum, Cromwell Road, SW7 $5 B D$, London, UK

Full list of author information is available at the end of the article
}

organisms, and organisms tracking geological and geographical changes $[3,4]$. Parasites can also serve as an independent source of information when evolutionary data on the host is insufficient [5]. Host specific ectoparasites have proven to be good proxies for resolving host population structure [6]. This is particularly true when an ectoparasite's life-cycle is entirely bound to a host individual resulting in co-speciation [e.g. [7-10]]. Nevertheless, co-speciation cannot be assumed in all systems where there are high levels of host specificity [e.g. $[11,12]]$ and careful investigation is required to
C Biomed Central

(C) 2011 Štefka et al; licensee BioMed Central Ltd. This is an Open Access article distributed under the terms of the Creative Commons Attribution License (http://creativecommons.org/licenses/by/2.0), which permits unrestricted use, distribution, and reproduction in any medium, provided the original work is properly cited. 
explain the complex associations between hosts and parasites.

A theoretical framework relating co-phylogenetic patterns with population genetic processes was defined by Rannala and Michalakis [4], who formulated assumptions under which congruence between host and parasite genealogies might be expected. These include the assumption of 1) no migration events between splitting populations and 2) coalescence of both host and parasite lineages in the ancestral population. This is difficult to achieve in situations where historical host-parasite associations may have been affected by recurrent migrations or climatic oscillations [e.g. $[13,14]]$, which is common in the fauna of mainland biomes.

Due to their relative isolation from mainland biota, restricted surface area and low probability of multiple colonization events, oceanic islands like Galápagos provide a convenient model to study co-phylogenetic patterns in hosts and parasites. Founding populations of island colonists are typically small in size and can only carry a limited number of gene alleles leading to rapid coalescence. Consequently the effects of selection and genetic drift quickly lead to genetic differentiation and the formation of new species [15].

The Galápagos islands, and Galápagos mockingbirds (Mimus spp.) in particular, have played a prominent role in research on island speciation. It was Charles Darwin's observation on the distinctiveness of Galápagos mockingbirds from their mainland relatives that provided much of the founding evidence for the idea that species evolve through time [16].

The geological origin of the Galápagos is very well understood [17-19]. This permits a detailed investigation of the impact of geographic isolation on the formation of population structure and speciation in Galápagos biota. Similar to other archipelagos that arose in the form of a successive chain of volcanic islands (e.g. Hawai'i), it has been proposed that the pattern of speciation by endemics follow the successional origin of islands in the chain, a phenomenon sometimes called the progression rule [20]. Geological evidence shows a strong northwest to southeast gradient in the age of the Galápagos islands (Figure 1). The youngest rise above a volcanic mantle hotspot in the northwest of the archipelago, and as they migrate along a tectonic plate transition towards the Southeast, the islands age and shrink due to erosion [18]. Thus the youngest islands (Isabela and Fernandina) are less than 0.5 million years (My) old, whereas the oldest extant islands (San Cristóbal and Española) are more than 2.5 My. Submerged islands of up to 14 My are found east of Española $[17,21]$ suggesting a much earlier origin is possible for at least some Galápagos biota. However, only a few instances of endemic fauna older than the age of the extant islands have

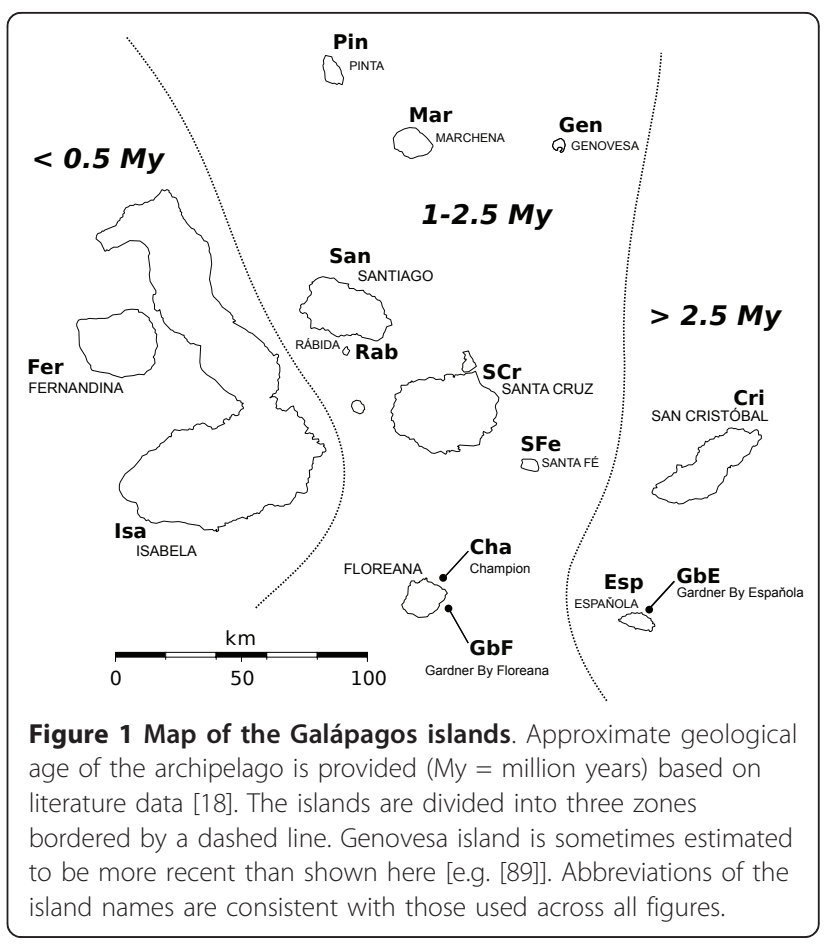

been confirmed, such as the Galapaganus weevils [22]. A vast majority of terrestrial species are younger than 2.5 My and also fit the progression rule pattern of colonization [for a review see [23]].

Exceptions to the progression rule include species capable of long distance dispersal, such as Darwin's finches [24] and some species of winged insects $[25,26]$, both of which show complex colonization histories. Arbogast et al. [27] showed that the mitochondrial DNA (mtDNA) phylogeny of mockingbirds largely follows the progression rule. This corresponds with low levels of long-distance dispersal as detected by population genetic surveys [28]. Comparing the level of divergence in Galápagos mockingbirds with mutation rates commonly found for coding mtDNA genes in birds Arbogast et al. [27] estimated that their colonisation of the Galápagos falls well within the age of present islands, and the distribution of the clades amongst particular islands was generally congruent with patterns of island age.

Arbogast et al. [27] also showed that the mtDNA data only partially fit the traditional taxonomy of Galápagos mockingbirds. Morphologically there are four nominal species of Galapágos mockingbirds, each with distinct geographic distributions. The Hood mockingbird (Mimus macdonaldi) inhabits Española, the San Cristóbal mockingbird (M. melanotis) is found on the island of the same name and the Floreana mockingbird $M$. trifasciatus is present on two islets adjacent to Floreana. The rest of the archipelago is populated by the Galápagos mockingbird 
(M. parvulus) (Figure 2). Despite belonging to three different nominal species, birds from the eastern islands of the archipelago (Española, San Cristóbal, and Genovesa) possess similar mtDNA haplotypes, while populations from Isabela in the west of the archipelago, are genetically more divergent from other $M$. parvulus populations than previously expected [27]. A study conducted by Hoeck et al. [28] shows that nuclear genetic data obtained using microsatellites largely agrees with the morphological distinction of species. Thus, at least some of the mtDNA differences are an exclusive feature of the mtDNA genealogy while other mtDNA sequences agree with the traditional taxonomy.

Discrepancies between mitochondrial and nuclear genealogies have been observed on multiple occasions in phylogeographic studies during the past two decades [29]. Several processes can explain these divergences, with secondary contact of previously separated lineages, ancestral allelic polymorphism and horizontal gene transfer representing the most common reasons for discordance. Typically, the age of the mtDNA lineages or alleles of nuclear genes predate the time of the population separation [30]. Therefore, the genetic pool of colonists may contain several copies of these haplotypes or alleles during the colonization event. Over time, random genetic drift leads to fixation of different mtDNA haplotypes and nuclear alleles in different populations. This ultimately leads to discordant genealogies amongst different loci, which hamper the interpretation of phylogeographic data based on analysis of single genes [31].

In this paper we reconstruct the common phylogeographic patterns shared between mockingbirds and their parasites inhabiting Galápagos islands using mtDNA and nuclear data. We evaluate the level of ancestral polymorphism affecting species phylogenies based on mtDNA data. Our analyses are partitioned by populations of all four mockingbird species and three associated parasites: an Astigmatid mite (Analges sp.) which has yet to be taxonomically described, an amblyceran parasitic louse (Myrsidea nesomimi) and an ischnoceran parasitic louse (Brueelia galapagensis). All three species of parasites are Galápagos endemics and are commonly associated with Galápagos mockingbirds [[32,33] authors' observation]. Despite sharing the same host spectrum, the three

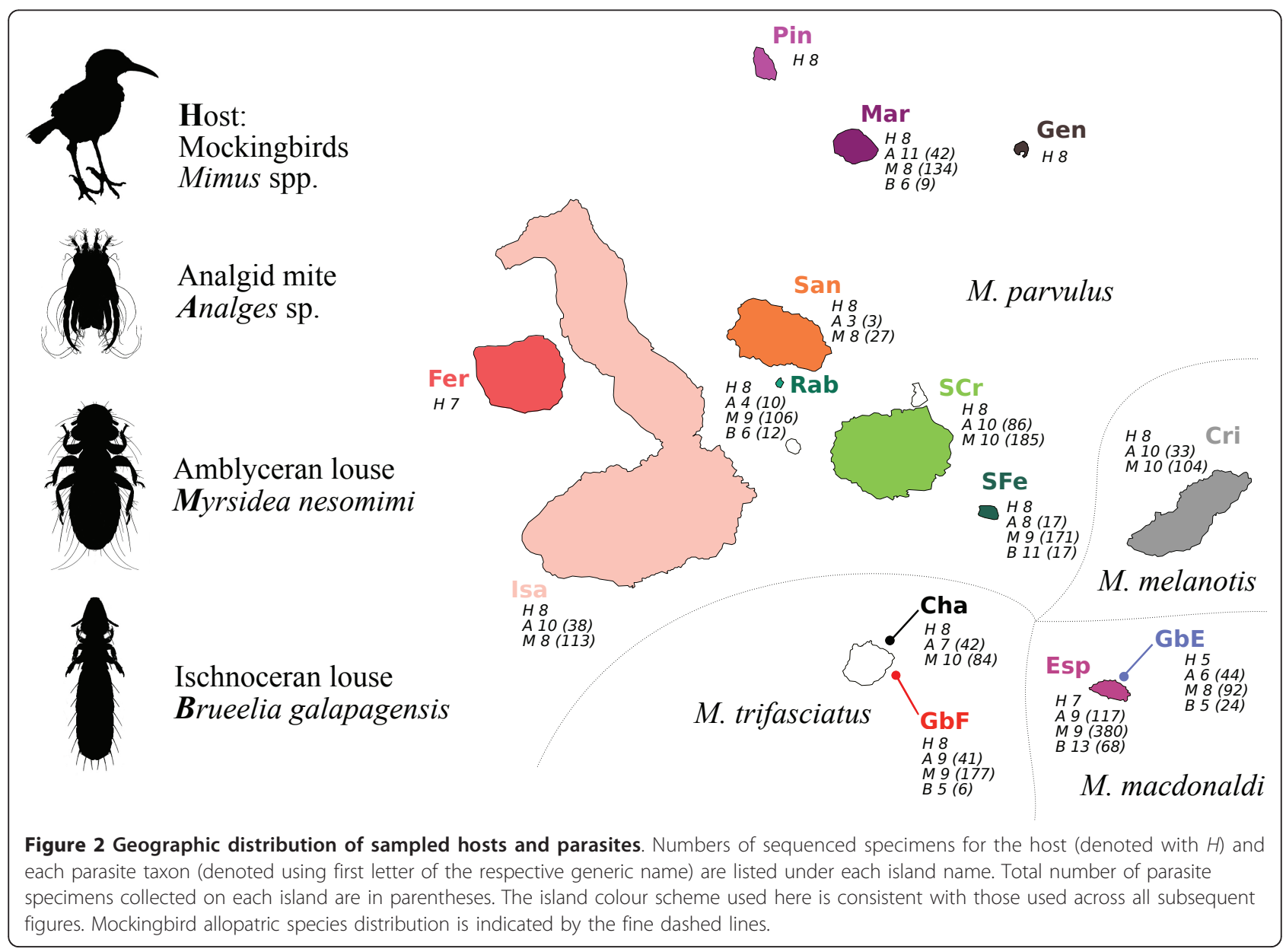


parasites represent three phylogenetically unrelated lineages $[34,35]$ that differ in their ecology. Feather mites of the genus Analges feed predominantly on feathers and are strictly host specific [36]. The two genera of chewing lice (Myrsidea and Brueelia) are known to differ in their feeding habits and in their levels of host specificity, which is strict in Myrsidea and more relaxed in Brueelia [e.g. $[32,37]]$. This assemblage of parasitic taxa allows us to discern shared evolutionary signal from unique evolutionary events affected by varying life history traits.

\section{Methods}

\section{Material collection}

Collection of both the host and parasite material was perfomed between 2004 and 2008 in the frame of previous research [28]. Mockingbird blood samples were obtained from 14 Galápagos islands and the birds were examined for ectoparasites on 11 of the 14 islands (see Figure 2). Myrsidea and Analges samples were found on all 11 islands, whereas Brueelia was found only on 6 islands. Birds were captured using mist nets or potter traps and a small blood sample was collected from a small puncture on the wing vein. Ectoparasites were collected from the plumage of the birds using dust ruffling [38]. Birds were ringed to prevent resampling and released immediately after sample collection. A single parasite specimen was analysed for each parasite taxon per host individual, with seven exceptions (four for Brueelia, two for Analges and one for Myrsidea) when the host infection rate was exceptionally low. For a complete list of analysed samples including GPS coordinates of the sampling localities and GenBank accession numbers see table in Additional file 1.

DNA extraction of parasite samples was performed using Qiagen's MicroDNA extraction kit following the voucher method of Cruickshank et al. [39]. After DNA extraction voucher specimens were either mounted on permanent slides or preserved in ethanol. MtDNA sequences of mockingbirds were amplified from DNA extractions made from blood samples previously used for a microsatellite population genetic study [28].

\section{Mitochondrial and nuclear DNA sequencing}

We sequenced a homologous $1050 \mathrm{bp}$ fragment of the Cytochrome oxidase subunit I (COI) gene in the mockingbirds and all three parasite taxa using a combination of previously described universal primers and dedicated primers based on sequences of related taxa available from GenBank (see Table 1 for primer sequences). The PCRs contained $20 \mu \mathrm{l}$ volume of: 1 to $2 \mu \mathrm{l}$ of extracted DNA solution, $5 \mathrm{pM}$ of each primer, $15 \mathrm{mM} \mathrm{MgCl}_{2}$, $10 \mathrm{mM}$ concentration of each dNTP, and 0.25 units of Taq polymerase. The PCR profile was as follows: $5 \mathrm{~min}$ at $95^{\circ} \mathrm{C}$ followed by 35 cycles of $1 \mathrm{~min}$ at $94^{\circ} \mathrm{C}, 45 \mathrm{sec}$ at the annealing temperature specified below and $1 \mathrm{~min}$
$15 \mathrm{sec}$ at $72^{\circ} \mathrm{C}$. The final elongation step was performed for $10 \mathrm{~min}$ at $72^{\circ} \mathrm{C}$. The annealing temperatures were $57^{\circ} \mathrm{C}$ for Mimus, $48^{\circ} \mathrm{C}$ for Analges and Brueelia, and $50^{\circ} \mathrm{C}$ for Myrsidea. To obtain complementary information on the population structure of ectoparasites independent of mitochondrial DNA, the Elongation factor 1 alpha $(E F 1 \alpha)$, a nuclear gene, was sequenced in two parasites, Brueelia and Analges. EF1-For3 and Cho10 primers [40] were used for both PCR amplification and sequencing. The PCRs contained the same concentrations of reagents as above and the PCR profile was as follows: $5 \mathrm{~min}$ at $95^{\circ} \mathrm{C}$ followed by 30 cycles of $1 \mathrm{~min}$ at $94^{\circ} \mathrm{C}, 40 \mathrm{sec}$ at $54^{\circ} \mathrm{C}$ and $45 \mathrm{sec}$ at $72^{\circ} \mathrm{C}$. The final elongation step was performed for $10 \mathrm{~min}$ at $72^{\circ} \mathrm{C}$. EF1-For3 and Cho10 primers did not reliably amplify in Myrsidea and thus the EF1 $\alpha$ gene was not analyzed for this species. Prior to sequencing COI and EF1 $\alpha$ PCR products were purified using Alkaline Phosphatase and Exonuclease I enzymes according to manufacturer's protocol (New England Biolabs). The COI PCRs were sequenced using newly designed species-specific internal primers (Table 1) aligning from the middle part of the sequence and extending towards the ends. To check for consistency of sequence reads at the ends, approximately $15 \%$ of sequences were also sequenced from 5' and 3' ends using PCR primers. Sequencing was performed either on an ABI 3730 sequencer (Applied Biosystems) or using a commercial service (Macrogen Inc., South Korea). Sequence contigs were prepared in Seqman (DNAstar) and alignments were created manually in Seaview 4.2 [41] without need for gap adjustments. Individual sequences were collapsed into haplotypes using Collapse 1.2 [42].

\section{Amplification of mockingbird microsatellites}

400 Mimus individuals covering the spectrum of 11 islands available for parasite sampling were genotyped using microsatellites. Extraction of DNA from blood on filter paper and amplification at 26 microsatellite loci (MpAAT18, 25, 26, 45, 83 and 96, and Nes01, 03, 04, 05, $06,07,08,10,11,12,13,14,15,16,17,18,19,20,22$ and 23) were performed as described previously [43]. Microsatellite loci were amplified in six independent multiplex reactions (Panel A-D, Hoeck et al., [43]; Panel E with MpAAT18, 25, 45 and 83; Panel F with MpAAT26 and 96 under the same PCR conditions as Panel B \& C). Fragment analyses were performed on a 3730 DNA Analyser using Gene-Scan-500 LIZ size standard (ABI) and Genemapper v.4 software (ABI) followed by manual proofreading of genotypes.

\section{Phylogenetic analysis of sequence data}

Three approaches were employed for genealogical reconstruction using COI haplotypes in Mimus, Analges and Myrsidea. Due to a very low level of sequence 
Table 1 PCR primers for amplification of the COI gene.

\begin{tabular}{|c|c|c|c|c|}
\hline Species & Primer name & Direction & Primer sequence & Reference \\
\hline \multirow[t]{4}{*}{ Mimus } & BirdF1_Nes & $\mathrm{F}$ & AACCAACCACAAAGATATCGGCAC & Modified from BirdF1 [87] \\
\hline & $\mathrm{COIH} \_\mathrm{Nes}$ & $\mathrm{R}$ & GGGCTACTACGTAGTAAGTGTCATGT & Modified from COI H7005 [74] \\
\hline & Nes_InF & $\mathrm{F}$ & CTCACCGACCGCAACCTCAA & This study \\
\hline & Nes_InR & $\mathrm{R}$ & GGATAGTATGGCTCATACTATTCCTATGTA & This study \\
\hline \multirow[t]{4}{*}{ Analges } & An_F & $\mathrm{F}$ & ATATCCACTAATCACAAAGATATTG & This study \\
\hline & $\mathrm{COI} \mathrm{H7005}$ & R & CCGGATCCACNACRTARTANGTRTCRTG & {$[74]$} \\
\hline & $A n \_I n F$ & $\mathrm{~F}$ & CCGTAATTITAATTCTACTITITITG & This study \\
\hline & $A n \_I n R$ & $\mathrm{R}$ & CAAACCCAGGTAAAATCAAAATATA & This study \\
\hline \multirow[t]{4}{*}{ Myrsidea } & Myr_F & $\mathrm{F}$ & ATATTGGYACTCTYTAYTTAATCTTTGGTT & This study \\
\hline & $\mathrm{COI} \mathrm{H7005}$ & $\mathrm{R}$ & CCGGATCCACNACRTARTANGTRTCRTG & {$[74]$} \\
\hline & Myr_InF & $\mathrm{F}$ & CCGAAATTTTAATACCTCTTTCTTTG & This study \\
\hline & Myr_InR & $\mathrm{R}$ & AGATTATACCAATGACCCCAAAACT & This study \\
\hline \multirow[t]{4}{*}{ Brueelia } & COI LCO1490 & $\mathrm{F}$ & GGTCAACAAATCATAAAGATATTGG & {$[88]$} \\
\hline & $\mathrm{COI} \mathrm{H7005}$ & $\mathrm{R}$ & CCGGATCCACNACRTARTANGTRTCRTG & {$[74]$} \\
\hline & Bru_InF & $\mathrm{F}$ & TCGTAATTTGAATTCTTCTTITITG & This study \\
\hline & Bru_InR & $\mathrm{R}$ & ACCCAAAAACTTCCTTCTTTCC & This study \\
\hline
\end{tabular}

polymorphism Brueelia was excluded from the phylogenetic analysis. Neighbor Joining (NJ) trees of haplotypes were obtained in PAUP*4.0b10 [44]. Maximum Likelihood (ML) phylogeny was reconstructed using PhyML 2.4.4 [45], and MrBayes 3.1 [46] was employed to perform Bayesian Inference (BI) from the data. In MrBayes two independent runs with 4 chains each and 30 million MCMC replications were performed for each dataset. The first 3 million replications at the beginning of the runs were discarded as burnin. The model of molecular evolution for all analyses was selected according to AIC and BIC criteria in jModeltest 12.2.0 [47]. HKY +I+G was selected for Analges, HKY+G for both Myrsidea and Mimus. Sequences of Analges sturninus (Genbank no.: GQ864342), Myrsidea eisenrati (AF545731) plus Mimus gundlachii (EF484222) and M. gilvus (EF484220), were used respectively as outgroups for the Analges, Myrsidea and Mimus datasets. The COI haplotype data and ML treefiles have been deposited in TreeBASE (http://www. treebase.org; study accession number S11770).

The branch support of NJ and ML phylogenies was obtained with 1000 bootstraps of the data in PAUP and PhyML, respectively. Convergence between estimated values of model parameters obtained in independent BI runs and their effective sampling sizes were checked using Tracer 1.5 [48]. Convergence of inferred BI topologies was inspected using AWTY [49].

Due to allelic variability and frequent occurrence of heterozygotes in EF1 $\alpha$ sequences of Analges, the allelic phase of specimens could not be unequivocally reconstructed from sequences obtained through direct sequencing. The heterozygous sites in the DNA sequence resulted in ambiguous nucleotides. Hence the EF1 $\alpha$ sequences were not analysed phylogenetically. Instead each position in the alignment for each specimen was scored either as homozygous or heterozygous (when ambiguous). Then the distribution of heterozygous or homozygous states for each site within the alignment was compared across island populations. These data were contrasted with gene genealogies obtained from the COI data. A similar approach was adopted for exploring the Brueelia EF1 $\alpha$ dataset, which was, on the contrary, extremely uniform and contained only one informative mutation (see Results section).

\section{Genealogy and population genetic statistics}

Due to extremely low levels of genetic variability in the COI Brueelia sequences, this dataset was not analysed using traditional phylogenetic reconstruction. Instead genealogical information of Brueelia and the other taxa was extracted from a haplotype network built using the program TCS 1.2 [50]. Estimates of genetic divergence were performed in Mega 5.0 [51]. For each taxon we calculated overall mean genetic distances (p-distances) [52] and pairwise genetic distances between the islands. The software DNASP 5.1 [53] was used to calculate per island statistics of haplotype diversity and nucleotide variability, and to perform neutrality tests (Tajima's D, Fu and Li's D) for all four organisms. Significance of the values obtained in neutrality tests was tested with 10,000 coalescence simulations of the data.

\section{Microsatellite data analysis}

To obtain an estimate of population structure in the mockingbirds that is independent of mtDNA genealogy, mockingbird microsatellite data were analysed using the Bayesian clustering algorithm in Structure 2.3.3 [54,55]. This analysis complements the estimates of genetic 
variability and differentiation presented in Hoeck et al [28]. The Bayesian clustering analysis was performed on an extended microsatellite dataset and provides an estimate of population structure by assigning individual specimens to genetic clusters. The analysis was run using 500,000 MCMC replications as a burnin followed by 1 million replications from which posterior distributions were drawn. To test for possibility of intra-island population structure the number of clusters $(\mathrm{K})$ modelled in the analysis was increased by one (to 12), compared to the 11 sampled islands. An admixture ancestry model with the assumption of correlated allele frequencies was used as a prior in the analysis. 15 independent runs of the analysis were performed to check for consistency of the results. Mean values of $\log$ likelihood, $\mathrm{L}(\mathrm{K})$, and the $\Delta \mathrm{K}$ statistics of Evanno et al. [56] were used to determine the optimum number of genetic clusters. Graphic visualisation of the results was prepared in Distruct 1.1 [57].

\section{MtDNA reconstruction of shared evolutionary history}

"BEAST [58] is a recently introduced extension of BEAST 1.6 [59] and supports Bayesian analysis allowing simultaneous estimation of phylogeny and node age. "BEAST was employed to perform comparison of mutation rates between Mimus and their Analges and Myrsidea ectoparasites. This software was originally developed to infer species trees from multilocus data, and was used here to reconcile the evolutionary history of the three organisms. This was achieved by inferring a multi-species tree from gene trees obtained from Mimus, Analges and Myrsidea, for which sampling was available on all 11 islands. Because no missing information on any of the analysed speciesisland combinations is allowed in the analysis, the Brueelia dataset containing data on only 6 islands was excluded. Datasets containing COI sequences of all available specimens (i.e. not collapsed into haplotypes) were used for all "BEAST analyses. These were run selecting the same models of molecular evolution as in the phylogenetic analysis. In the first analysis relative evolutionary rates between the three gene trees (Mimus, Analges, Myrsidea) were estimated. A prior of 1.0 was set on the rate for Mimus, allowing relative estimation of rates for the parasites. Clock-like behaviour of the Mimus dataset was tested in baseml, a program from the PAML package [60] and it was rejected $\left(\mathrm{X}^{2}=39.44, \mathrm{df}=23, \mathrm{P}<=0.02\right)$. Therefore uncorrelated lognormal relaxed clock priors were selected for rate comparisons. The analysis was run for 100 million MCMC replications and a speciation birth-death process was selected as a tree prior. Two independent runs were performed and convergence between the estimates of parameters was assessed using Tracer 1.5 [48]. Results of the two runs were combined in Logcombiner 1.6.1 [59] with $10 \%$ burnin. A separate analysis was performed to estimate the topology of the species tree and the dates of the co-speciation events. In this analysis the age of the root of the species tree was defined with a lognormal prior, using a mean set to 2.9 million years ago (Mya) and standard deviation set to 0.4 . This calibration prior sets the highest probability of the age of the root to the estimated geologic age of Española, the oldest extant island of the archipelago [18] but also allows for an earlier origin on the submerged islands east of Española [17]. An uncorrelated relaxed clock with uninformative priors was selected for the three gene trees. Two independent runs were conducted with 500 million MCMC replications each. As above the convergence between runs was inspected in Tracer 1.5 [48] and results were combined in Logcombiner 1.6.1 [59]. We are aware that restricting the analysis with only one calibration point is insufficient to provide precise estimates of the node ages. However, our aim was solely to provide ordinal information on the succession of origin of the fauna in particular regions of the archipelago, rather than to provide exact dates of diversification events.

Complementary to the "BEAST analysis, the tree topologies of Mimus and its parasites (Analges and Myrsidea) were reconciled using the program Jane [61]. This program allows mapping parasite trees onto host phylogeny using a heuristic approach with the so-called Genetic Algorithm. The TreeMap costs model [62] was used to score the numbers of evolutionary events (co-speciations, host switches, duplications and losses). Then the statistical significance of the cost of identified co-speciations is tested using permutation analysis. Tree topologies obtained in the ML analysis and pruned to contain only the main mitochondrial lineages were supplied to the program. Mapping was run with Genetic Algorithm set to 500 generations with population size 300 . The permutations were run both randomising the tips of the trees and randomising the parasite tree topology using the sample size of 1000 .

\section{Geophylogenies}

To visualise the level of congruence between gene genealogies and incorporate information on the geographic distribution of the specimens, mtDNA phylogenies were converted to KML files, which can be viewed using the freely available Google Earth application [63]. The online tool GeoPhylo 2-4 [64] was used to convert ML phylogenies of Mimus, Analges and Myrsidea, and a multi-species tree into KML files. For the visualisation purposes a NJ tree of Brueelia was generated in PAUP*4.0b10 [44] using JC distance model and converted into KML format. The root of the tree was assigned according to a mutation split identified in the EF1 $\alpha$ sequences that divides the populations into two groups - the Española and the rest of the archipelago (see Results section). Rooting with an outgroup was not possible in Brueelia due to the very low 
genetic diversity of Brueelia samples and a lack of sequences for close relatives in GenBank.

\section{Results}

107 sequences of the COI gene were obtained in Mimus, 86 in Analges, 98 in Myrsidea, and 45 in Brueelia. These sequences were collapsed into $25,71,37$ and 8 haplotypes, respectively. 51 EF1 $\alpha$ sequences were obtained in Analges and 29 in Brueelia. The list of sequenced specimens and associated haplotype numbers are available in Additional file 1.

\section{Genetic comparison of populations}

COI sequence data show that Analges is genetically the most diverse organism, both in terms of number of haplotypes $(\mathrm{Hd})$ and nucleotide diversity $(\mathrm{Pi})$, followed by Myrsidea (Table 2). Mimus shows considerably smaller levels of population variability, while Brueelia is the most conserved taxon with only a few mutations spread across the $1050 \mathrm{bp}$ alignment and each island population made up of one to three haplotypes. This is reflected in the values of genetic divergence (p-distances) seen for the four taxa (Additional file 2). The overall mean genetic divergence is highest for Analges followed by Myrsidea, Mimus and Brueelia. Similarly a comparison of distances between particular islands shows that the values are in general highest for Analges and lowest for Brueelia.

Neutrality tests performed separately for each island population for all taxa generally show moderately negative values, and are only significantly different from expected values in a few cases. Populations showing significantly negative values of both Tajima's D and Fu\&Li's D are Española in Mimus, Marchena in Analges and Santiago and Gardner by Floreana (GbF) in Myrsidea (Table 2). Negative values caused by an excess of low frequency polymorphisms usually indicate population size expansion after an earlier bottleneck or a selective sweep [65]. Only the Mimus population on Rábida shows significantly positive values (again for both statistics) suggesting population shrinkage or an effect of balancing selection. These tests could only be performed for populations containing two or more haplotypes, thus many Mimus populations comprising single haplotypes could not be tested because they lacked variability ( $\mathrm{Hd}$ and $\mathrm{Pi}=0$, Table 2 ). The Champion and Gardner by Española (GbE) population of Myrsidea, and the Rábida populations of Brueelia similarly comprise single haplotypes.

\section{Mitochondrial phylogenies}

COI topology of the Mimus haplotypes (Figure 3) is largely congruent with the earlier results of Arbogast et al [27], who analysed a different set of mockingbird samples using shorter fragments of the COI gene in combination with 2 other mtDNA loci. The most basal split separates mockingbird populations inhabiting the South-East islands (Española, GbE, San Cristóbal and Genovesa) from the rest of the archipelago. Isabela and Fernandina formed another monophyletic lineage followed by GbF and Champion, which comprise a single haplotype. The rest of the islands form a single lineage. This picture largely follows the traditional taxonomy of Galápagos mockingbirds with two exceptions. 1) As in Arbogast et al. [27] the Genovesa population (M. parvulus) was grouped into a single clade with the San Cristóbal ( $M$. melanotis) and Española (M. macdonaldi) populations. 2) Due to the near basal position of Isabela and Fernandina populations, the $M$. parvulus is polyphyletic with respect to $M$. trifasciatus. These data contradict current taxonomic and nuclear DNA (microsatellite) results [28] that group the Genovesa population with the neighbouring M. parvulus populations from the North-Western islands of the archipelago. Hoeck et al. [28] also found that the Española and San Cristóbal populations, although closely related, form two clearly distinguishable clusters based on microsatellite distance data.

The topologies of the COI phylogenies obtained for Myrsidea and Analges sp. parasites broadly follow that of the host phylogeny. The split between populations from the Southeast islands of the archipelago are located at the root in all phylogenies (Figure 3). Most islands or groups of islands form very well supported monophyletic lineages suggesting a deep origin for mitochondrial clades associated with island populations. A few exceptions where the bootstrap and posterior probability support is weaker are also seen. These are usually located near the base of the trees and probably reflect rapid succession of diversification events in ancestral populations of the corresponding mitochondrial lineages. Despite the general congruence of the three phylogenies, the topology of relationships between some of the clades differs both between the two parasites and with their host. Most discordant was the clustering of the Champion population of Myrsidea with a clade found on Santa Fé and Santa Cruz. For the other two taxa (Mimus and Analges), Champion samples were grouped with Gardner by Floreana populations, which was expected, since both islands are small islets adjacent to Floreana and host remnant populations of the endangered Floreana mockingbird that went extinct on Floreana in the late $19^{\text {th }}$ century. This means the two populations are of recent common origin. Indeed, the mockingbird mtDNA sequences show a single haplotype for the two islets, complying with the close relationship and reduced population sizes.

\section{Population genealogies and EF1 $\alpha$ variability}

The pattern of population structure seen in the mtDNA haplotype networks shows several strongly differentiated lineages in Mimus, Myrsidea and Analges (Figure 4). 
Table 2 Genetic diversity of sampled populations and neutrality test results.

\begin{tabular}{|c|c|c|c|c|c|c|c|c|c|c|c|c|c|c|c|c|c|c|c|c|}
\hline \multirow[t]{2}{*}{ Island } & \multicolumn{4}{|c|}{ No. Specim. } & \multicolumn{4}{|c|}{ No. Haps. } & \multicolumn{4}{|l|}{$\mathrm{Hd}$} & \multicolumn{4}{|l|}{$\mathrm{Pi}$} & \multicolumn{4}{|c|}{ Tajima's D/Fu\&Li's D } \\
\hline & $\bar{H}$ & $A$ & $M$ & B & $H$ & $A$ & $M$ & B & $H$ & $A$ & $M$ & B & $H$ & $A$ & $M$ & B & H & $A$ & $M$ & B \\
\hline Española & 7 & 8 & 9 & 13 & 4 & 8 & 7 & 2 & 0.714 & 1.000 & 0.893 & 0.318 & 0.0011 & 0.0090 & 0.0016 & 0.0014 & $-1.43 /-1.51$ & $-0.59 / 0.02$ & $-1.28 /-0.13$ & $-1.32 /-0.37$ \\
\hline Gardner by Española & 5 & 6 & 8 & 5 & 1 & 5 & 4 & 1 & 0.000 & 0.933 & 0.714 & 0.000 & 0.0000 & 0.0087 & 0.0017 & 0.0000 & $x$ & $0.45 / 0.51$ & $0.61 /-0.07$ & $x$ \\
\hline San Cristóbal & 8 & 10 & 10 & & 2 & 9 & 2 & . & 0.250 & 0.978 & 0.467 & . & 0.0002 & 0.0074 & 0.0005 & & $-1.05 /-1.13$ & $-0.59 /-0.67$ & $0.82 / 0.80$ & \\
\hline Champion & 8 & 7 & 10 & . & 1 & 3 & 1 & . & 0.000 & 0.667 & 0.000 & & 0.0000 & 0.0008 & $x$ & . & $x$ & $0.21 /-0.06$ & $x$ & . \\
\hline Gardner by Floreana & 8 & 9 & 9 & 5 & 1 & 6 & 3 & 2 & 0.000 & 0.833 & 0.417 & 0.400 & 0.0000 & 0.0025 & 0.0007 & 0.0008 & $x$ & $-0.43 /-0.30$ & $-1.51 /-1.68$ & $-0.97 /-0.97$ \\
\hline Santa Fé & 8 & 8 & 9 & 11 & 1 & 6 & 5 & 2 & 0.000 & 0.893 & 0.417 & 0.182 & 0.0000 & 0.0018 & 0.0019 & 0.0002 & x & $-1.36 /-1.36$ & $-0.56 /-0.37$ & $-1.13 /-1.29$ \\
\hline Santa Cruz & 8 & 10 & 10 & & 2 & 10 & 4 & & 0.250 & 1.000 & 0.583 & & 0.0005 & 0.0115 & 0.0010 & & $-1.30 /-1.41$ & $-0.70 /-0.44$ & $-1.15 /-0.28$ & \\
\hline Santiago & 8 & 3 & 8 & & 3 & 3 & 4 & & 0.464 & x & 0.643 & . & 0.0005 & $x$ & 0.0007 & & $-1.30 /-1.41$ & x & $-1.45 /-1.57$ & \\
\hline Rábida & 8 & 4 & 9 & 6 & 6 & 3 & 2 & 1 & 0.893 & 0.833 & 0.500 & 0.000 & 0.0060 & 0.0011 & 0.0005 & 0.0000 & $1.76 / 1.53$ & $0.52 / 0.59$ & 0.99/0.84 & $x$ \\
\hline Isabela & 8 & 10 & 8 & . & 2 & 9 & 7 & . & 0.536 & 0.978 & 0.964 & & 0.0005 & 0.0101 & 0.0053 & . & $1.17 / 0.89$ & $-0.59 /-0.68$ & $0.03 / 0.29$ & \\
\hline Marchena & 8 & 11 & 8 & 6 & 4 & 9 & 4 & 3 & 0.786 & 0.945 & 0.643 & 0.600 & 0.0044 & 0.0038 & 0.0029 & 0.0006 & $-0.10 / 0.37$ & $-2.03 /-2.39$ & $-1.05 /-0.88$ & $-1.13 /-1.16$ \\
\hline Fernandina & 7 & & & & 2 & & & & 0.286 & . & & & 0.0003 & & & & $-1.01 /-1.05$ & & & \\
\hline Genovesa & 8 & & & & 1 & & & & 0.000 & . & . & & 0.0000 & & & & x & & & \\
\hline Pinta & 8 & & & & 2 & . & & & 0.250 & & & & 0.0002 & & & & $-1.05 /-1.13$ & & & \\
\hline
\end{tabular}

Abbreviations and comments: "Hd" haplotype diversity; "Pi" nucleotide diversity. Values of significant neutrality tests $(\mathrm{P}<0.05)$ are in bold. "." no sampling for a given taxon; " $\mathrm{x}$ " statistics not performed due to lack of variability $(<2$ haplotypes) or too few samples $(<4)$; species abbreviations $(H, A, M, B)$ as in Figure 2 . 

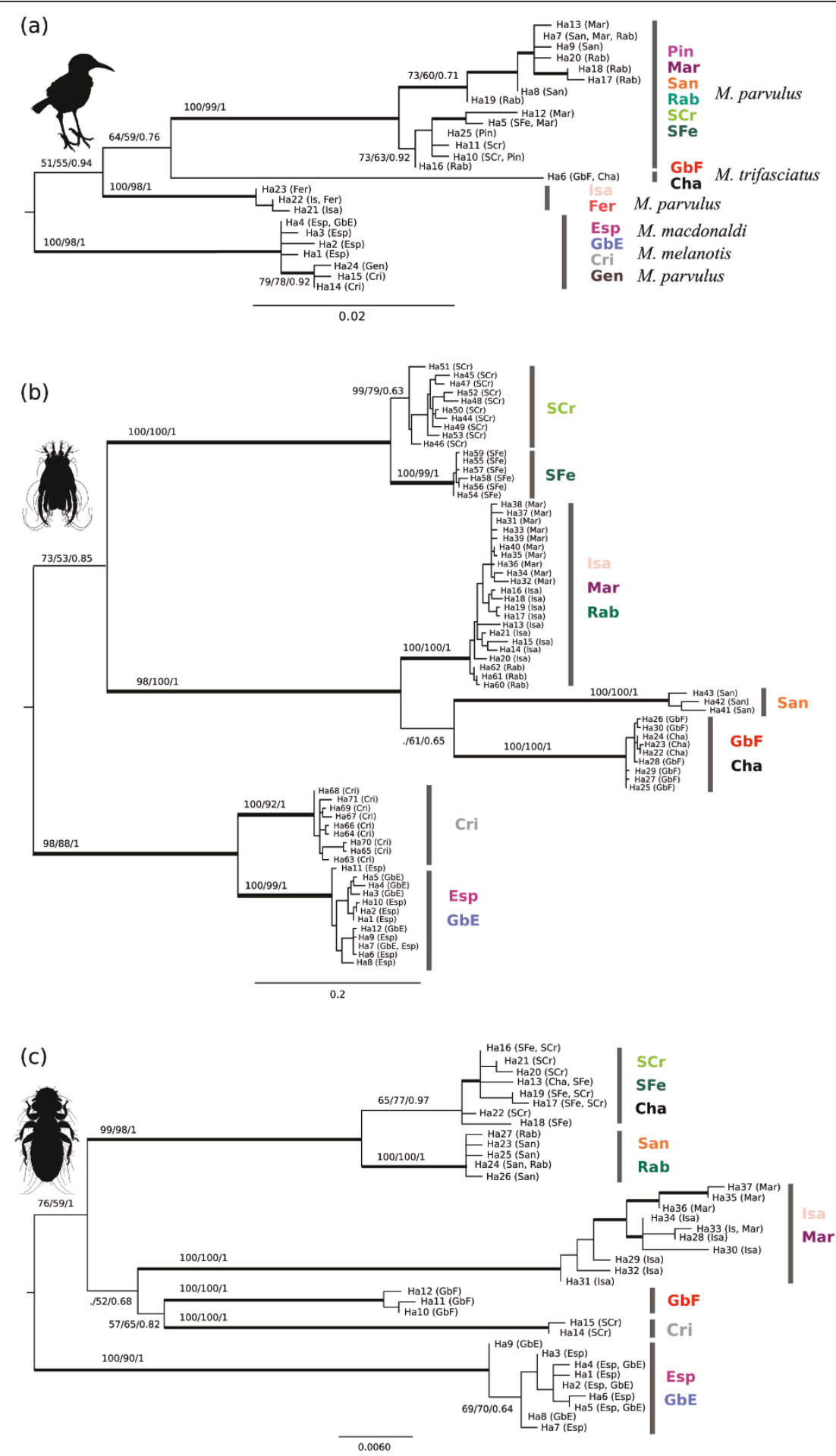

Figure 3 Maximum likelihood phylogenies of COI haplotypes. (a) Mimus, (b) Analges and (c) Myrsidea. Bootstrap values and posterior probabilities (NJ/ML/BI) for major clades are indicated. Clades with bootstrap support above $75 \%$ and Bl posterior probabilities higher than 0.95 are depicted in bold. Outgroups are not shown.

In contrast, the haplotype network of Brueelia shows very little sequence variation (Figure $4 \mathrm{~d}$ ). Despite this, several Brueelia populations contain exclusive haplotypes (e.g.
Española together with GbE and Marchena), highlighting a degree of genetic isolation between the islands. The Brueelia dataset of $29 \mathrm{EF} 1 \alpha$ sequences supports this 
(a)

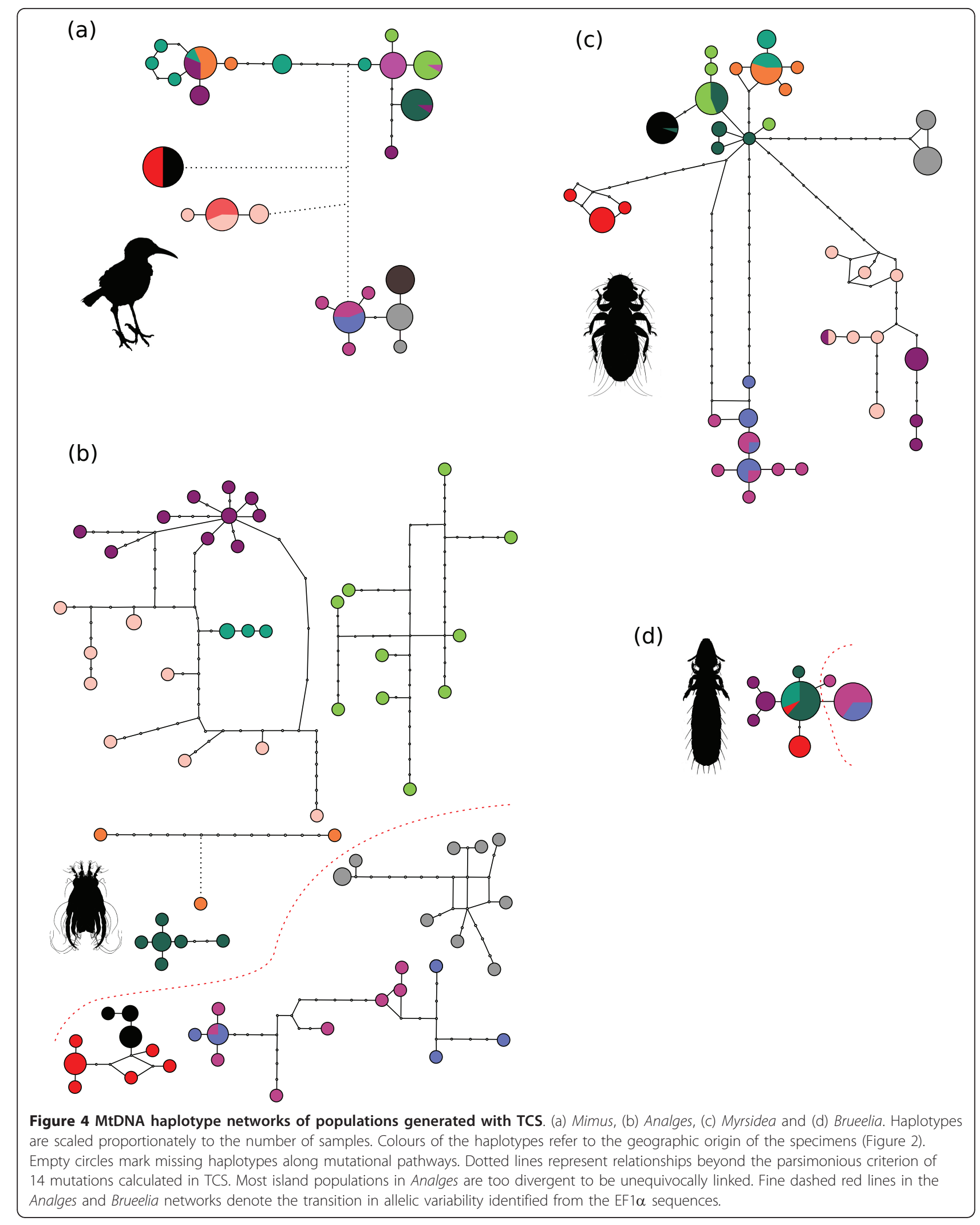


view. The EF1 $\alpha$ gene is almost invariable, out of the 347 bp sequenced, there were only 10 mutated sites, which were mostly singletons. Only one mutation, which was shared among multiple specimens, is informative and it differentiates Española and GbE populations from the rest. This confirms that the deepest genetic separation in Brueelia lies between the SE islands and the rest of the archipelago (fine red line in Figure $4 \mathrm{~b}$ and $4 \mathrm{~d}$ ), as identified in the other three taxa using outgroup sequences (Figure 3).

In contrast to Brueelia, the pattern of haplotype distribution in Analges shows an extreme level of diversification, with each island (with the exception of GbE) comprising an exclusive set of haplotypes (Figure $4 \mathrm{~b}$ ). Less population structure is seen in Myrsidea, where a few haplotypes are shared between Isabela and Marchena, Santa Fé and Santa Cruz, Santiago and Rábida, and one haplotype was shared between Champion and Santa Fé (Figure 4c). One haplotype was also shared between Champion and Santa Fé. Much lower levels of differentiation are found in Mimus, where several haplotypes are shared between two or three islands in the central and North-West part of the archipelago. Analges also shows extremely high levels of allelic variability in EF1 $\alpha$ sequences. The distribution of genetic variation is geography dependent, showing clear structure between the South-East and North-West (Figure 4b). Samples from Española, GbE, San Cristóbal, Champion and GbF only contain a few heterozygous positions in the alignment, with 47 out of the total of 58 mutated sites present as fixed homozygotes. In contrast, populations from the other six islands show a much higher proportion of heterozygous sites (data not shown).

\section{Microsatellite analysis of mockingbirds}

The pattern of population structure in Mimus obtained using Structure software shows hierarchical structuring of genetic diversity (Figure 5). The steepest change in the $\Delta \mathrm{K}$ statistics of Evanno et al. [56] was identified for $\mathrm{K}=3$ (Figure $5 \mathrm{a}$ ). The three determined clusters are represented by 1) Española with GbE and San Cristóbal, 2) Champion and GbF, and 3) the rest of the archipelago (Figure 5c). Despite M. melanotis from San Cristóbal being clustered with $M$. macdonaldi, there is a slight

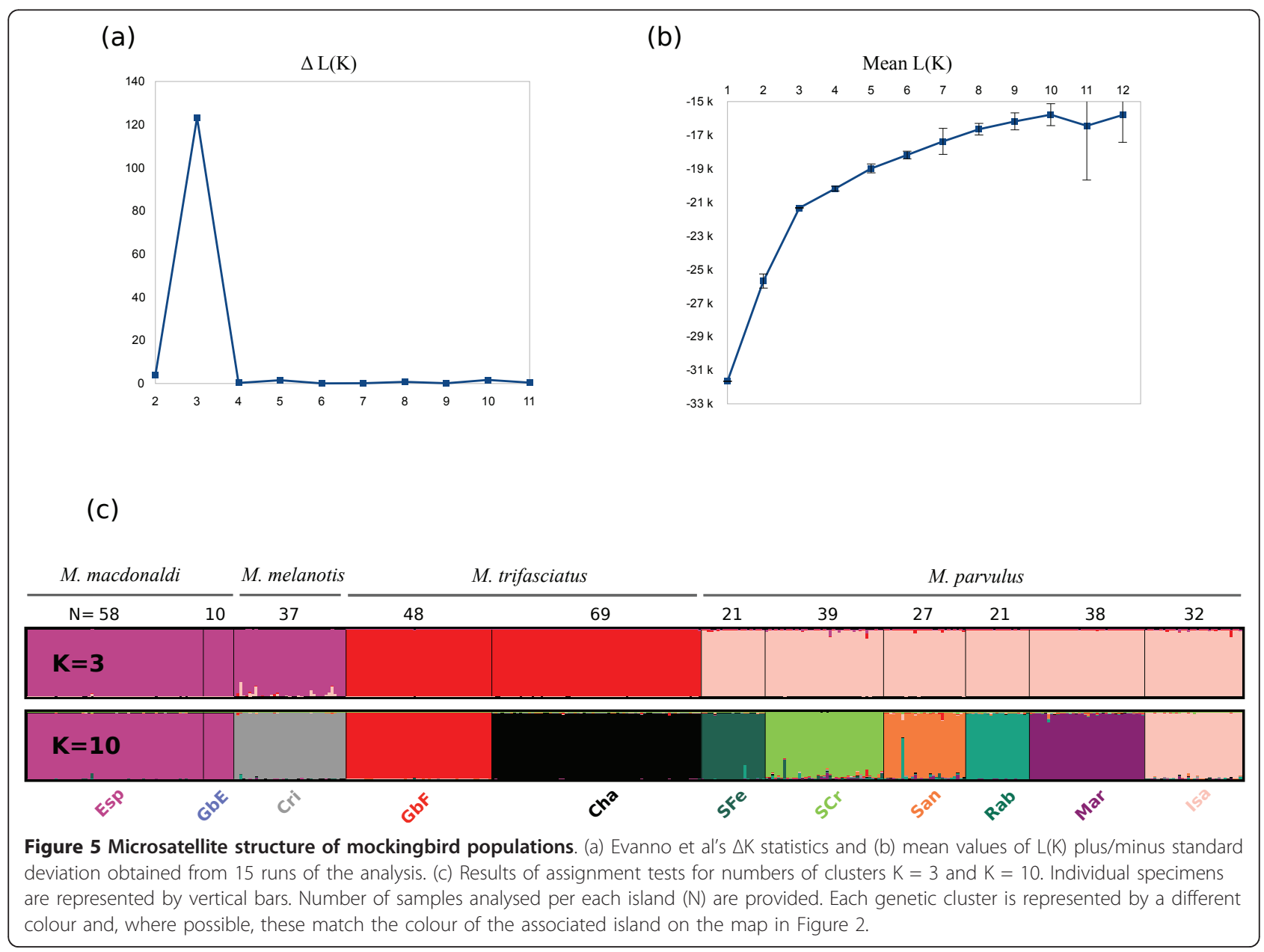


difference in the genetic composition between the two species: The San Cristóbal population possesses partially mixed genotypes (Figure 5c).

The $\Delta \mathrm{K}$ statistics are known to pick up the deepest level of genetic structure (i.e. evolutionary oldest) for datasets containing hierarchical data [56]. In contrast L (K) identifies much shallower divergences. The values of the mean $\mathrm{L}(\mathrm{K})$ levels off at $\mathrm{K}=10$ (Figure $5 \mathrm{~b}$ ), where a geographically determined pattern of population structure is seen with all but two of the islands comprising exclusive clusters (Figure 5c). The exception is GbE which shares the same genetic cluster with its parent island of Española. This is almost certainly due to the very small geographic distance between GbE and Española (approximately $1 \mathrm{~km}$ ) that allows for frequent exchange of migrants. With $\mathrm{K}=10$ each Mimus species belongs to a separate cluster (M. melanotis and M. macdonaldi) or is split into several clusters (M. parvulus and M. trifasciatus; Figure 5c).

\section{Estimation of shared evolutionary signal}

To reconcile the evolutionary history of the parasites and their hosts, a putative "multi-species" tree was reconstructed in "BEAST. The topology of the resulting tree (Figure 6) is compatible with the geological history of the islands [18], the host microsatellite data in Hoeck et al [28] and the microsatellite analysis presented here. Posterior probabilities $[\mathrm{PP}]$ are above 0.95 in all but three nodes (Figure 6b). The branches with lower support are amongst the shortest ones on the tree. One of these branches joins

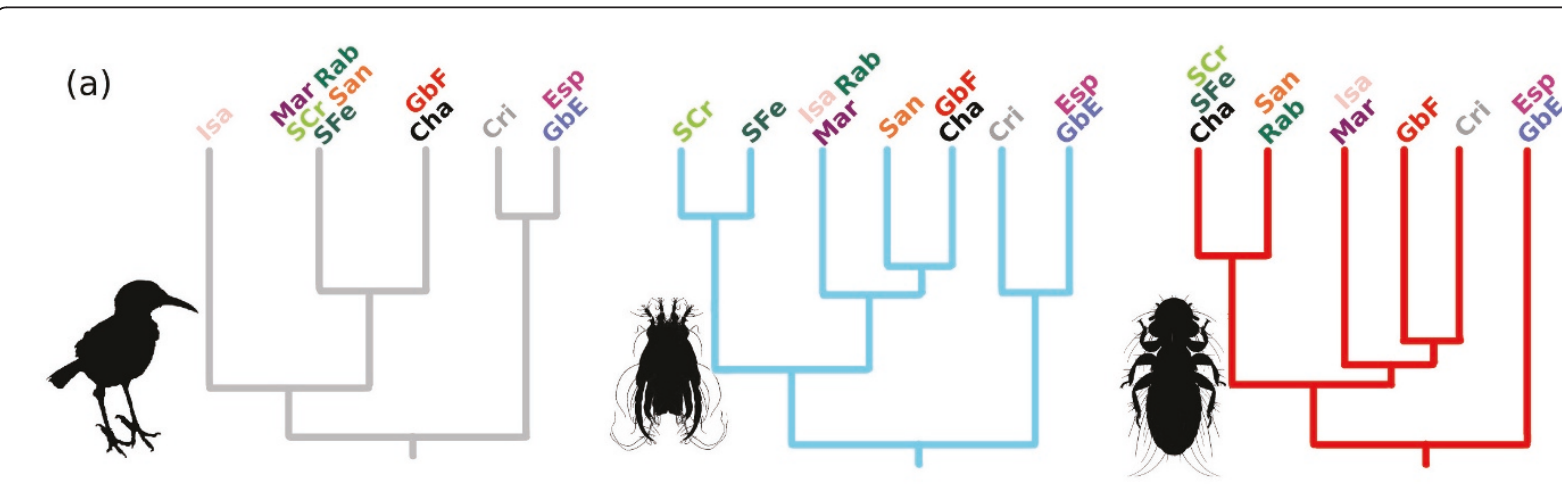

(b)
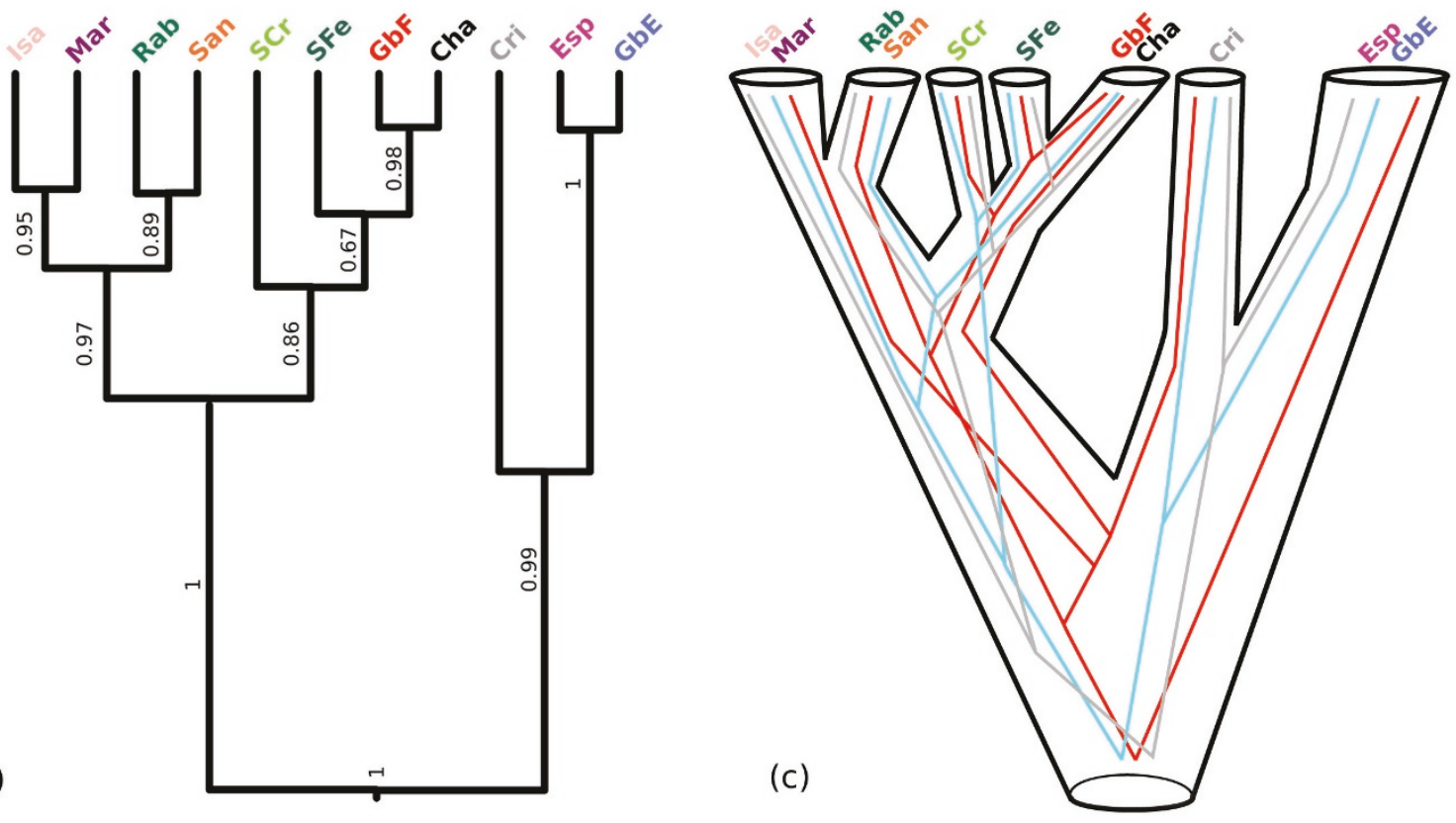

Figure 6 MtDNA reconstruction of the evolutionary history shared between taxa. Schematic representation of individual gene trees (phylogenies from Figure 3) are provided (a). The multi-species tree (b) was generated in *BEAST and individual gene genealogies are plotted against putative evolutionary history of taxa based on the topology of the multi-species tree (c). 
Rabida with Santiago (PP = 0.89), the other two join Santa Cruz with Santa Fe (PP = 0.86) and Santa Fe with the lineage containing Champion and GbF ( $\mathrm{PP}=0.67)$. As is the case with the individual mitochondrial genealogies, the basal split lies between the South East (SE) islands (Española, GbE, San Cristóbal) and the rest. The clade containing SE populations is further divided separating Española with GbE from San Cristóbal. A second major clade comprising islands from the central and northern part of the archipelago shows sub-structuring into two lineages. One consists of populations from Champion, GbF, Santa Fé and Santa Cruz, while the other comprises the northern-most islands clustering Isabela together with Marchena and Rábida with Santiago (Figure 6b). Despite several incongruences between individual tree genealogies observed for particular taxa, the independent phylogenetic signals become evident when sequences are jointly analysed. This is best seen when individual genealogies are contrasted with the resulting species tree in Figure 6c, or using a Google Earth visualisation available in Additional File 3. "BEAST was also used to estimate relative evolutionary rates between the host and their parasites. Results are congruent with the differences in genetic variability estimated in DNASP. Analges shows the fastest mutation rate and is approximately 9 times faster than Mimus (mean $=8.70,95 \%$ Highest Posterior Density interval [HDP]: 6.81-10.00). Myrsidea is considerably slower than Analges but still significantly faster than its host (mean = 1.87, 95\% HDP: 1.09-2.74). Despite the statistically significant result of the baseml test highlighting deviation from clock-like behaviour, the values of standard deviations of the uncorrelated lognormal clock obtained in "BEAST were below 1 for all three taxa (lowest in Analges $=0.20$, highest in Myrsidea $=0.69$ ). Values below 1 indicate only moderate deviation from clock-like behaviour [66], thus our estimates of relative mutation rates were not significantly affected by these deviations.

Estimates of node ages from the multi-species tree have very wide confidence intervals due to the single calibration point (see below). However, observed values lie within the date ranges determined from geological data [18], and are indicative of the time axis for the succession of speciation events. The basal split between the SE islands and the rest of archipelago is within the prior interval, with mean value of 1.20 Mya (95\% HDP: 2.220.39). Subsequent splits are much younger, with the age of the split between San Cristóbal and Española estimated at $0.43 \mathrm{Mya}$ (95\% HDP: 1.01-0.05) and 0.19 Mya (95\% HDP: 0.43-0.04) for the split between the two groups of North-Western islands (see Additional file 4 for a complete chronogram). The multi-species estimates probably reflect the final stage in the separation of faunas as opposed to estimates obtained from the same analysis of individual species genealogies that showed slightly earlier separation of mtDNA clades. For instance, the age of the basal split showed values of $1.58 \mathrm{Mya}$ (95\% HDP: 3.24-0.41) in Analges, 1.54 Mya (95\% HDP: 3.14-0.38) in Mimus and 1.53 (95\% HDP: 3.1-0.39) in the genealogy of Myrsidea (Additional file 4).

Results obtained in the reconciliation analysis with Jane show significant level of co-speciation in the MimusAnalges association ( $\mathrm{P}<0.03$, in both permutation tests). 4 co-speciations, 2 duplications, 1 host switch and 1 loss were identified. In contrast only 1 co-speciation with 3 host switches and 4 duplications was found for the Mimus-Myrsidea association. This solution was did not show significant cospeciation in the permutation tests $(\mathrm{P}<0.87)$. More co-speciation events for the MimusMyrsidea dataset could be manually enforced to reflect better relative timing of splitting diversification events between the two trees. However, these adjustments would come at higher cost because they would inflate the number of losses or host switches. Figures containing mapped phylogenies for both host-parasite associations are available in Additional file 5.

\section{Discussion}

We studied the co-evolutionary patterns between populations of four host and three ectoparasite species living in close ecological association on the Galápagos islands using mtDNA (COI) and nuclear loci (EF1 $\alpha$ sequences, microsatellites). Despite varying levels of genetic variability between species and loci, reconstructed phylogeographic patterns show that the population structure between host and parasite lineages is broadly congruent and their diversification is sequentially ordered according to the geological age of each island. In all cases the deepest genetic splits occur between SE islands and the rest of the archipelago (Figures 3 and 6). Most incongruent events between individual gene phylogenies are likely to be attributable to the effect of ancestral polymorphism. Assessing the contribution of stochastic processes on the evolutionary patterns obtained for each species is possible through reconciling the phylogeny of these taxa. Output from this simultaneous analysis agrees with the traditional classification of the mockingbird species and with Mimus microsatellite results much more closely than when the Mimus mtDNA data are analysed separately.

\section{Ancestral polymorphism and phylogeography}

The occurrence of ancestral polymorphism followed by a process of lineage sorting creates differences in topologies between gene trees and species trees of closely related taxa. When unrecognized, this makes accurate interpretation of genealogical data extremely difficult [e.g. [67]]. Ancestral polymorphism affects both nuclear and mitochondrial genes, but is more problematic for mitochondrial data due to their haploid nature. Despite this, 
mtDNA remains one of the most valuable resources for phylogeographic inference, mainly due to its fast mutation rate and lack of recombination, which clusters individuals at the intra-specific level [68]. To obtain an unambiguous picture of species history several independent (i.e. nuclear) loci are recommended to be co-analysed with mitochondrial data [29]. Such nuclear loci might include sequences of nuclear genes or multilocus data like AFLP, microsatellites, and SNP's. Unfortunately, nuclear coding genes often do not provide sufficient resolution to detect all relationships in recently diverged taxa, and non-coding fast evolving genes like rDNA spacers (ITS1, ITS2) often create paralogues prone to stochastic evolution [e.g. [69,70]]. Furthermore, developing multilocus markers de novo is prohibitively time consuming and expensive when required for multiple taxa.

Here we show that pooling mtDNA data from several organisms, when there is reasonable a priori expectation of them having a shared evolutionary history, improves confidence in the inferred phylogeographic patterns. Parasites, and host specific ectoparasites in particular, can predict the population structure of their hosts [e.g $[1,71]]$, and in some cases can reveal more about the host's recent evolution than the host data in isolation. Whiteman et al [72] showed that the population structure of lice parasitizing Galápagos hawks suggests that the hawks (Buteo galapagoensis) colonised the archipelago very recently. This is not evident in independent studies of the hawk populations themselves because the genetic differences have not had time to fix. In the case of the mockingbird parasites, the effect of parasite isolation through host specificity is strongly enhanced by physical allopatric isolation of the host populations on different islands. Hoeck et al [28] measured pairwise genetic distances (Nei's Ds) between mockingbird populations from 15 different islands. These data show that populations of mockingbirds occupying separate islands represent distinguishable genetic pools.

A similar picture of strongly isolated mockingbird populations was obtained in the present study using the Bayesian clustering algorithm in the Structure software, where populations are delimited solely by the genetic character of the individuals without prior information on their geographic distribution. This strongly indicates that mockingbirds do not regularly migrate between islands. The ecological dependencies between mockingbirds and their obligate parasites mean that the lice and mites similarly lack opportunities for frequent inter-island migration. Hence, most of the cases where parasite genealogies do not match the inferred multi-species tree (Figure 6) are likely to be a result of ancestral polymorphism in the distribution of haplotypic lineages across the islands, and are not due to recent migrations followed by switches to different host clades. The distribution of genetic diversity in mtDNA haplotypes between the islands strongly supports such a view. For example, nearly all incongruences between particular genealogies are observed in samples from younger North-Western islands where the processes of genetic drift followed by accumulation of mutations has had less time to act. Furthermore, there is evidence that even in the case of younger islands, population structure is not affected by recent migration. For example, Analges, which exhibits a remarkably high mutation rate (see discussion below), shows no haplotypes that are shared between any of the islands, including the youngest ones like Isabela, Rábida and Marchena (haplotype network in Figure 4b). Populations of mites on individual islands diverged from each other through mutation and the resulting population structure has not been stirred up by any migration.

There is one possible exception to this general pattern. Despite the close geographic distance and putative recent common origin of Floreana mockingbirds on Champion and GbF [73], the populations of Myrsidea on the two islands are strikingly different (Figure 3c). The Champion population constitutes a single haplotype that is very closely related to haplotypes from Santa Fé. The Champion haplotype is even shared with one specimen from Santa Fé (see haplotype network in Figure 4c). This close link suggests that a recent migration event between these islands is a more probable explanation than shared ancestry. Such a migration would require an unknown louse vector since neither Floreana mockingbirds nor Analges mites exhibit recent links with Santa Fé. Unfortunately, unlike the other three taxa where microsatellite or EF1 $\alpha$ data provide additional clues, no nuclear markers were available for Myrsidea, thus resolving this problem with confidence will require additional data. This probably also affected the position of Champion and GbF islands on the multi-species tree (Figure $6 \mathrm{~b}$ ). Nodes joining these islands together with Santa Fe and Santa Cruz have the lowest posterior probabilities on the multi-species tree ( 0.67 and 0.86 respectively) and this topology is also in conflict with the traditional taxonomy of mockingbirds. The close relationship of the Champion and GbF populations of M. trifasciatus with those on Santa Cruz and Santa Fé make the M. parvulus populations inhabiting Santa Cruz, Santa Fé and the youngest parts of the archipelago paraphyletic. This contradicts the microsatellite data, which clearly distinguish all M. parvulus populations from M. trifasciatus on Champion and GbF.

Like other species tree reconciliation methods based on multi-species coalescent models [58], the "BEAST algorithm assumes no horizontal gene transfer in the gene genealogies. In one instance this assumption is violated by our data through the possibility of a recent introduction of Myrsidea from Santa Fé to Champion island, which is analogous to a host switch in host-parasite 
reconciliation methods. This is the only case where the incongruence between the topologies is located on the terminal nodes. We can reasonably suppose that the deeper incongruences are caused by ancient ancestral polymorphism, which is accommodated in the "BEAST analysis. Excluding this terminal event, other instances of incongruence do not significantly affect our interpretation of the reconciled multi-species tree.

An improved fit between the genealogies of Analges and Mimus compared to the Myrsidea - Mimus association is also seen in the results produced by the Jane analysis, where only one co-speciation was inferred for the latter pair. Instead Jane identified a relatively large number of host switches or duplications. This highlights a pitfall of the multi-gene "BEAST analysis which cannot accommodate host switching events. Nevertheless, Jane cannot incorporate ancestral polymorphism, which is critical for analysing evolutionary recent associations. For this reason we consider the reconciliation analysis via tree mapping less suitable for the Galápagos dataset. Furthermore, traditional reconciliation analysis is only as good as the supplied trees. By utilising tree topologies instead of raw sequential data for all available specimens, the analysis is limited to the solutions permitted by the tree topologies and cannot assess uncertainty in the input data in a way that is possible in the Bayesian analysis.

\section{Mockingbird conservation}

Understanding the origin of the Champion population of Myrsidea is also interesting with respect to the conservation of the endangered Floreana mockingbird. Floreana mockingbirds on Champion and GbF represent remnants of the bird population extinct on Floreana. Bird populations on both islets show dramaticaly low levels of genetic variability, as identified through the haplotype diversity presented here and by Arbogast et al [27]. Microsatellite data generated by Hoeck et al [73] also show very short coalescence times for the populations on the two islets. Nevertheless, both Hoeck et al [28] and the Structure analysis performed here group the two Floreana mockingbird populations together when compared to other Galápagos mockingbird species. More detailed knowledge about the epidemiology and evolutionary history of Myrsidea on Champion and $\mathrm{GbF}$ would provide valuable data relevant to a tentative reintroduction of mockingbirds on Floreana. Additional genetic loci and extended sampling would help to assess the level of host-parasite co-adaptation in the two populations, and help assess risks connected with uniting the populations on Floreana.

\section{Louse Taxonomy}

Palma and Price [33] identify two subspecies of Myrsidea nesomimi within the Galápagos based on morphological data. These subspecies comprise $M$. n. nesomimi (found on Epaňola, GbE and on the two islets of Floreana) and M. n. borealis (occupying the rest of the archipelago). Genetic data presented here clearly separate the Epaňola and GbE population of Myrsidea from the rest of the archipelago (Figure 3c). However, the Champion and GbF populations seem to be genetically distinct from Española and, at least in the case of GbF, also from the other Galápagos islands.

\section{Mutation rates}

Greater population differentiation has occurred in the parasites (excluding Brueelia) than in their hosts (Figure 4). This is congruent with the faster parasite mutation rate identified in the "BEAST analysis. When compared to their hosts, elevated mutation rates are a common feature in lice and might be explained through the shorter louse generation time leading to quicker accumulation of new mutations [74]. Relative evolutionary rates of mockingbird Myrsidea are approximately two-fold faster than their hosts, which is in line with the rate difference commonly found in other studies of lice and their vertebrate hosts [e. g. [74-77]]. However, the nine-fold faster mutation rate of Analges is unexpectedly high. This remarkable difference requires further attention, not least because the length of the generation time in Analges is probably not different to lice. Although exact data on Analgid mites are lacking, the generation times of taxonomically related Sarcoptid mites are two to three weeks [78], similar to most parasitic lice [37]. To our knowledge, there are no studies of feather mites that provided relative mutational rate estimates for comparison. However, the fast genomic evolution in Analges is likely to be a lineage specific character. In addition to Analges, Astigmatid mites, containing many other parasitic and free-living species, have been shown to have significantly faster mutation rates than other mite groups [35].

\section{Louse ecology influencing genetic patterns}

As representatives of two separate louse suborders the louse species analysed in this study differ considerably with respect to their ecology and evolutionary origins. Brueelia, as other ischnoceran lice, feed on feathers, whereas amblyceran Myrsidea include host body fluids in their diet. Amblycera are therefore more exposed to the host's immune response than Ischnocera [37]. Such interaction may promote selection towards host specific forms in Myrsidea and might accelerate their genetic differentiation relative to ischnoceran Brueelia.

Other ecological characters may also explain the different levels of genetic differentiation in these different suborders of parasitic lice. The pattern reported here of lower levels of intra-specific variability in Ischnocera relative to Amblycera has also been identified in other taxonomic studies of lice. For example, Bueter et al. [79] compared 
levels of intra-generic genetic diversity between Brueelia and Myrsidea parasitizing thrushes (genus Catharus, Passeriformes). Their data show decreased genetic diversity and lack of co-speciation in Brueelia when compared to their hosts. This could be explained by increased dispersal capabilities in Brueelia, either through direct contact of host organisms or via phoresis (transport) on hippoboscid flies parasitizing various bird hosts [80].

Comparative studies of genetic differences at a very low (intra-specific) evolutionary levels are rare in lice [for exceptions see [81-83]] but in these cases different dispersal capabilities have also been suggested as important factors contributing to the differences in population structure. The role of phoresis in facilitating the dispersal of lice has been documented on numerous occasions in Ischnocera with a majority of cases citing Brueelia attached to hippoboscid flies. In contrast, phoretic associations involving Amblycera are very rare [80]. Hippoboscid flies are present on Galápagos mockingbirds [authors' observation] making dispersal through phoresis a possible explanation for the lack of inter-island differentiation in Brueelia. However, it is improbable that hippoboscids could migrate between islands without being attached to a bird. Thus any migration of Brueelia between islands, whether vectored by hippoboscids or not, is likely to involve another bird host. Brueelia galapagensis has been recorded from several other species of hosts including the Small Ground Finch (Geospiza fuliginosa) $[32,84]$ which is endemic to the Galápagos and is capable of migration between islands [24,85]. Although records of B. galapagensis from non-specific hosts (i.e. other than Mimus) have been questioned and may be attributed to contamination [R.L. Palma, personal communication] it is possible that B. galapagensis occasionally occurs on the Small Ground Finch as stragglers. The lack of genetic structure in B. galapagensis might be explained by phoretic transfer to the Small Ground Finch and the inter-island migration of this species, followed by recurrent phoretic transfer back to mockingbirds.

Brueelia also show very little intra-population variability, which is compatible with low population sizes of the parasite recovered during collecting. Despite large numbers of mockingbirds inspected for lice, Brueelia was absent on many islands, especially on larger islands of the archipelago and in those instances when Brueelia was present, its abundance and prevalence were very low in comparison to Myrsidea (Figure 2). This might suggest lower levels of adaption for Brueelia on mockingbirds compared to the other two parasitic taxa. We can only speculate as to why Brueelia is missing on larger islands. It may be the case that Brueelia is only capable of surviving on mockingbirds that exist in smaller, genetically depleted host populations. For instance, a similar link between host genetic diversity and the prevalence of an ischnoceran parasite, was reported in populations of a wild lesser kestrel, Falco naumanni and their lice, Degeeriella rufa [86].

\section{Conclusions}

Using mitochondrial DNA sequences and nuclear data we studied 400 samples of recently diverged Galápagos mockingbirds and 229 specimens of 3 species of their parasites (Analges, Myrsidea and Brueelia). We found that co-phylogeographic patterns inferred on the level of single gene genealogies (for Mimus, Analges and Myrsidea) are considerably impacted by differential distribution of ancestral polymorphism. In contrast, extremely low genetic variability and lack of co-phylogeographic congruence was found in Brueelia. These differences may be explained by life history traits in Brueelia such as their dispersal capabilitity, abundance, and lower levels of host specificity. A more accurate picture of the phylogeographic history of these lineages, congruent with the geological history of the islands and with available nuclear data was obtained through a joint analysis of data for the three co-evolving groups. We show that pooling genetic data for several organisms living in close ecological association improves the inference of phylogeographic histories in recently diverged species.

\section{Additional material}

Additional file 1: List of samples sequenced for $\mathrm{COI}$ and EF1 $\alpha$.

Additional file 2: Matrices of mean genetic divergence ( $p$-distances) for the $\mathrm{COI}$ gene.

Additional file 3: *BEAST chronograms. Provided are multi-species chronogram (a) and chronograms for Mimus (b), Analges (c) and Myrsidea (d) datasets. Tip labels on the multi-species tree are the same as in Figure 1. Tip labels on the individual species trees are abbreviations of the island names from Figure 1 and voucher numbers from Additional file 1. Mean values of ages for major clades are provided with blue bars ranging the $95 \%$ highest posterior probability interval.

Additional file 4: Zipped archive containing KML files for each of the taxon phylogenies. These data files should be viewed in Google Earth [http://www.google.com/earth].

Additional file 5: Host-parasite phylogenies mapped with Jane software. Results for Mimus-Analges (a) and Mimus-Myrsidea (b) associations are shown. Hollow circles mark co-speciations, solid circles mark duplications. Host switches are marked by arrows and losses by dashed lines. Host trees are in black, mapped parasite histories are in blue. Yellow nodes indicate another location of equal cost exists, red nodes mark the solution with the lowest cost. Taxon labels were assigned as species and island abbreviations as shown in Figures 1 and 2.

\section{Acknowledgements}

We thank the Galápagos National Park Service for permission to conduct this research (Permit No. PC-48-10) and the Charles Darwin Foundation for assistance. The authors are grateful to Václav Hypša, Kevin Johnson and two anonymous reviewers for useful comments on the manuscript. This work was supported by Marie Curie Fellowship (project Galápagos, no. 235123, FP7-PEOPLE-IEF-2008) and by the Czech Science Foundation (project No. 
206/08/1019). Part of the work was carried out by using the resources of the Computational Biology Service Unit at Cornell University.

\section{Author details}

'Entomology Department, Natural History Museum, Cromwell Road, SW7 5BD, London, UK. ${ }^{2}$ Faculty of Science, University of South Bohemia and Biology Centre ASCR, Institute of Parasitology, Branisovska 31, 37005 Ceske Budejovice, Czech Republic. ${ }^{3}$ Institute of Evolutionary Biology and Environmental Studies, University of Zurich, Winterthurerstrasse 190, 8057 Zurich, Switzerland.

\section{Authors' contributions}

JS sequenced the studied taxa, performed computional analyses and drafted the manuscript. VS concieved the idea of studying host-parasite co-evolution in mockingbirds, provided guidance with data analyses and contributed to drafting the manuscript. $\mathrm{PH}$ concluded fragment analysis of the mockingbird microsatellites. PH and LK collected all study material and helped with finishing the manuscript text. All authors read and approved the final manuscript.

\section{Received: 7 April 2011 Accepted: 3 October 2011}

Published: 3 October 2011

\section{References}

1. Nieberding C, Morand S, Libois R, Michaux JR: A parasite reveals cryptic phylogeographic history of its host. Proc Biol Sci 2004, 271:2559-2568.

2. Linz B, Balloux F, Moodley Y, Manica A, Liu H, Roumagnac P, Falush D, Stamer C, Prugnolle F, van der Merwe SW, Yamaoka Y, Graham DY, PerezTrallero E, Wadstrom T, Suerbaum S, Achtman M: An African origin for the intimate association between humans and Helicobacter pylori. Nature 2007, 445:915-918.

3. Page RDM, Charleston MA: Trees within trees: phylogeny and historical associations. Trends Ecol Evol 1998, 13:356-359.

4. Rannala B, Michalakis Y: Population genetics and cospeciation: from process to pattern. In Tangled Trees: phylogeny, cospeciation and coevolution. Edited by: Page RDM. Chicago: University of Chicago Press, Illinois; 2002:120-143.

5. Nieberding CM, Olivieri I: Parasites: proxies for host genealogy and ecology? Trends Ecol Evol 2007, 22:156-165.

6. Whiteman NK, Parker PG: Using parasites to infer host population history: a new rationale for parasite conservation. Animal Conservation 2005, 8:175-181

7. Clayton DH, Bush SE, Goates BM, Johnson KP: Host defense reinforces host-parasite cospeciation. Proc Natl Acad Sci 2003, 100:15694-15699.

8. Hafner MS, Demastes JW, Spradling TA, Reed DL: Cophylogeny between pocket gophers and chewing lice. In Tangled Trees: phylogeny, cospeciation and coevolution. Edited by: Page RDM. Chicago: University of Chicago Press, Illinois; 2002:195-220.

9. Morelli M, Spicer GS: Cospeciation between the nasal mite Ptilonyssus sairae (Acari: Rhinonyssidae) and its bird hosts. Systematic and Applied Acarology 2007, 12:179-188.

10. Hughes J, Kennedy M, Johnson KP, Palma RL, Page RDM: Multiple cophylogenetic analyses reveal frequent cospeciation between pelicaniform birds and Pectinopygus lice. Syst Biol 2007, 56:232-251.

11. Banks JC, Palma RL, Paterson AM: Cophylogenetic relationships between penguins and their chewing lice. J Evol Biol 2006, 19:156-166.

12. Gómez-Díaz E, González-Solís J, Peinado MA, Page RDM: Lack of hostdependent genetic structure in ectoparasites of Calonectris shearwaters. Mol Ecol 2007, 16:5204-5215.

13. Nieberding CM, Durette-Desset MC, Vanderpoorten A, Casanova JC, Ribas A, Deffontaine V, Feliu C, Morande S, Libois R, Michaux JR: Geography and host biogeography matter for understanding the phylogeography of a parasite. Mol Phylogenet Evol 2008, 47:538-554.

14. Štefka J, Hypša V: Host specificity and genealogy of the louse Polyplax serrata on field mice, Apodemus species: A case of parasite duplication or colonization? Int J Parasitol 2008, 38:731-741.

15. Barton $\mathrm{NH}$ : Natural selection and random genetic drift as causes of evolution on islands. Philos Trans R Soc Lond B Biol Sci 1996, 351:785-794.

16. Darwin CR: Narrative of the surveying voyages of His Majesty's Ships Adventure and Beagle between the years 1826 and 1836, describing their examination of the southern shores of South America, and the
Beagle's circumnavigation of the globe. Journal and remarks 1832-1836. London, UK: Henry Colburn; 1839.

17. Christie DM, Duncan RA, McBirney AR, Richards MA, White WM, Harp KS Fox CG: Drowned islands downstream from the Galápagos hotspot imply extended speciation times. Nature 1992, 355:246-248.

18. White WM, McBirney AR, Duncan RA: Petrology and geochemistry of the Galápagos Islands: Portrait of a pathological mantle plume. J Geophys Res-Solid Earth 1993, 98:533-563.

19. O'Connor JM, Stoffers P, Wijbrans JR, Worthington TJ: Migration of widespread long-lived volcanism across the Galápagos Volcanic Province: Evidence for a broad hotspot melting anomaly? Earth Planet Sci Lett 2007, 263:339-354

20. Funk VA, Wagner WL: Biogeographic patterns in the Hawaiian Islands. In Hawaiian Biogeography: Evolution on a Hot Spot Archipelago. Edited by: Wagner WL, Funk VA. Washington, DC: Smithsonian Institution Press; 1995:379-419.

21. Werner R, Hoernle K, Bogaard PVD, Ranero C, Huene RV, Korich D: Drowned 14-m.y.-old Galápagos archipelago off the coast of Costa Rica: Implications for tectonic and evolutionary models. Geology 1999, 27:499-502.

22. Sequeira AS, Lanteri AA, Scataglini MA, Confalonieri VA, Farrell BD: Are flightless Galapaganus weevils older than the Galápagos Islands they inhabit? Heredity 2000, 85:20-29.

23. Parent $C E$, Caccone A, Petren $\mathrm{K}$ : Colonization and diversification of Galápagos terrestrial fauna: a phylogenetic and biogeographical synthesis. Philos Trans R Soc Lond B Biol Sci 2008, 363:3347-3361.

24. Petren K, Grant PR, Grant BR, Keller LF: Comparative landscape genetics and the adaptive radiation of Darwin's finches: the role of peripheral isolation. Mol Ecol 2005, 14:2943-2957.

25. Sequeira AS, Lanteri AA, Albelo LR, Bhattacharya S, Sijapati M: Colonization history, ecological shifts and diversification in the evolution of endemic Galápagos weevils. Mol Ecol 2008, 17:1089-107.

26. Schmitz P, Cibois A, Landry B: Molecular phylogeny and dating of an insular endemic moth radiation inferred from mitochondrial and nuclear genes: the genus Galagete (Lepidoptera: Autostichidae) of the Galápagos Islands. Mol Phylogenet Evol 2007, 45:180-192.

27. Arbogast BS, Drovetski SV, Curry RL, Boag PT, Seutin G, Grant PR, Grant BR, Anderson DJ: The origin and diversification of Galápagos mockingbirds. Evolution 2006, 60:370-382

28. Hoeck PEA, Bollmer JL, Parker PG, Keller LF: Differentiation with drift: a spatio-temporal genetic analysis of Galápagos mockingbird populations (Mimus spp.). Philos Trans R Soc Lond B Biol Sci 2010, 365:1127-1138.

29. Avise JC: Phylogeography: retrospect and prospect. J Biogeogr 2009, 36:3-15.

30. Nichols R: Gene trees and species trees are not the same. Trends Ecol Evol 2001, 16:358-364.

31. Funk DJ, Omland KE: Species-level paraphyly and polyphyly: frequency, causes, and consequences, with insights from animal mitochondrial DNA. Annu Rev Ecol Syst 2003, 34:397-423.

32. Price RD, Hellenthal RA, Palma RL, Johnson KP, Clayton DH: The Chewing Lice: World Checklist and Biological Overview. Illinois Natural History Survey Special Publication 2003.

33. Palma RL, Price RD: The species of Myrsidea Waterston (Insecta: Phthiraptera: Menoponidae) from the Galápagos Islands, with descriptions of new taxa. Tuhinga 2010, 21:135-146.

34. Johnson KP, Yoshizawa K, Smith VS: Multiple origins of parasitism in lice. Proc Biol Sci 2004, 271:1771-1776.

35. Dabert M, Witalinski W, Kazmierski A, Olszanowski Z, Dabert J: Molecular phylogeny of acariform mites (Acari, Arachnida): strong conflict between phylogenetic signal and long-branch attraction artifacts. Mol Phylogenet Evol 2010, 56:222-2241.

36. Proctor HC: Feather mites (Acari: Astigmata): ecology, behavior, and evolution. Annu Rev Entomol 2003, 48:185-209.

37. Marshall AG: The ecology of ectoparasitic insects. Academic Press, London, UK; 1981.

38. Clayton DH, Drown DM: Critical evaluation of five methods for quantifying chewing lice (Insecta: Phthiraptera). J Parasitol 2001, 87:1291-1300

39. Cruickshank RH, Johnson KP, Smith VS, Adams RJ, Clayton DH, Page RD: Phylogenetic analysis of partial sequences of elongation factor 1 alpha identifies major groups of lice (Insecta: Phthiraptera). Mol Phylogenet Evol 2001, 19:202-215. 
40. Danforth BN, Ji SQ: Elongation factor-1 alpha occurs in two copies in bees: implications for phylogenetic analysis of EF-1 alpha sequences in insects. Mol Biol Evol 1998, 14:381-390.

41. Gouy M, Guindon S, Gascuel O: SeaView version 4: a multiplatform graphical user interface for sequence alignment and phylogenetic tree building. Mol Biol Evol 2010, 27:221-224.

42. Posada D: Collapse: describing haplotypes from sequence alignments. [http://darwin.uvigo.es/software/collapse.html].

43. Hoeck PEA, Bucher TB, Wandeler P, Keller LF: Microsatellite primers for the four Galápagos mockingbird species (Mimus parvulus, M. macdonaldi, M. melanotis and M. trifasciatus). Mol Ecol Resour 2009, 9:1538-1541.

44. Swofford DL: Paup*: Phylogenetic Analysis Using Parsimony (*and Other Methods). Sinauer Associates, Inc. Publishers, Sunderland, Massachusetts; 2001.

45. Guindon S, Gascuel O: A simple, fast, and accurate algorithm to estimate large phylogenies by maximum likelihood. Syst Biol 2003, 52:696-704.

46. Ronquist F, Huelsenbeck JP: MRBAYES 3: Bayesian phylogenetic inference under mixed models. Bioinformatics 2003, 19:1572-1574

47. Posada D: JModelTest: phylogenetic model averaging. Mol Biol Evol 2008, 25:1253-1256.

48. Rambaut A, Drummond AJ: TRACER.[http://tree.bio.ed.ac.uk/software/tracer].

49. Nylander JAA, Wilgenbusch JC, Warren DL, Swofford DL: AWTY (are we there yet?): a system for graphical exploration of MCMC convergence in Bayesian phylogenetics. Bioinformatics 2008, 24:581-583.

50. Clement M, Posada D, Crandall K: TCS: a computer program to estimate gene genealogies. Mol Ecol 2000, 9:1657-1660

51. Tamura K, Peterson D, Peterson N, Stecher G, Nei M, Kumar S: MEGA5: Molecular evolutionary genetics analysis using Maximum Likelihood, Evolutionary Distance, and Maximum Parsimony methods. Mol Biol Evol 2011.

52. Nei M, Kumar S: Molecular Evolution and Phylogenetics Oxford University Press, New York; 2000.

53. Librado P, Rozas J: DnaSP v5: a software for comprehensive analysis of DNA polymorphism data. Bioinformatics 2009, 25:1451-1452.

54. Falush D, Stephens M, Pritchard JK: Inference of population structure using multilocus genotype data: linked loci and correlated allele frequencies. Genetics 2003, 164:1567-1587.

55. Falush D, Stephens M, Pritchard JK: Inference of population structure using multilocus genotype data: dominant markers and null alleles. $\mathrm{Mol}$ Ecol Notes 2007, 7:574-578

56. Evanno G, Regnaut S, Goudet J: Detecting the number of clusters of individuals using the software STRUCTURE: a simulation study. Mol ECOl 2005, 14:2611-2620.

57. Rosenberg NA: DISTRUCT: a program for the graphical display of population structure. Mol Ecol Notes 2004, 4:137-138.

58. Heled J, Drummond AJ: Bayesian inference of species trees from multilocus data. Mol Biol Evol 2010, 27:570-580.

59. Drummond AJ, Rambaut A: BEAST: Bayesian evolutionary analysis by sampling trees. BMC Evol Biol 2007, 7:214

60. Yang Z: PAML 4: phylogenetic analysis by maximum likelihood. $\mathrm{Mol}$ Biol Evol 2007, 24:1586-1591.

61. Conow C, Fielder D, Ovadia Y, Libeskind-Hadas R: Jane: a new tool for the cophylogeny reconstruction problem. Algorithms Mol Biol 2010, 5:16.

62. Charleston MA, Robertson DL: Preferential host switching by primate lentiviruses can account for phylogenetic similarity with the primate phylogeny. Syst Biol 2002, 51:528-535.

63. Google Earth. [http://www.google.com/earth]

64. Hill AW, Guralnick RP: GeoPhylo: an online tool for developing visualizations of phylogenetic trees in geographic space. Ecography 2010, 33:633-636.

65. Simonsen KL, Churchill GA, Aquardo CF: Properties of statistical tests of neutrality for DNA polymorphism data. Genetics 1995, 141:413-429.

66. Drummond AJ, Ho SYW, Phillips MJ, Rambaut A: Relaxed phylogenetics and dating with confidence. PLOS Biology 2006, 4:e88.

67. Anderson TJ: The dangers of using single locus markers in parasite epidemiology Ascaris as a case study. Trends Parasitol 2001, 17:183-188

68. Zink RM, Barrowclough GF: Mitochondrial DNA under siege in avian phylogeography. Mol Ecol 2008, 17:2107-2121.

69. Buckler-Iv ES, Ippolito A, Holtsford TP: The evolution of ribosomal DNA divergent paralogues and phylogenetic implications. Genetics 1997, 145:821-832.
70. Kraálovaá-Hromadovaá I, Štefka J, Špakulová M, Orosová M, Bombarová M, Hanzelová V, Bazsalovicsová E, Scholz T: Intra-individual internal transcribed spacer 1 (ITS1) and ITS2 ribosomal sequence variation linked with multiple rDNA loci: A case of triploid Atractolytocestus huronensis, the monozoic cestode of common carp. Int J Parasitol 2010, 40:175-181.

71. Toon A, Hughes JM: Are lice good proxies for host history? A comparative analysis of the Australian magpie, Gymnorhina tibicen and two species of feather louse. Heredity 2008, 101:127-135.

72. Whiteman NK, Kimball RT, Parker PG: Co-phylogeography and comparative population genetics of the threatened Galápagos hawk and three ectoparasite species: ecology shapes population histories within parasite communities. Mol Ecol 2007, 16:4759-4773.

73. Hoeck PEA, Beaumont MA, James KE, Grant RB, Grant PR, Keller LF: Saving Darwin's muse: evolutionary genetics for the recovery of the Floreana mockingbird. Biol Lett 2010, 6:212-215.

74. Hafner MS, Sudman PD, Villablanca FX, Spradling TA, Demastes JW, Nadler SA: Disparate rates of molecular evolution in cospeciating hosts and parasites. Science 1994, 265:1087-1090.

75. Reed DL, Smith VS, Hammond SL, Rogers AR, Clayton DH: Genetic analysis of lice supports direct contact between modern and archaic humans. PloS Biol 2004, 2:1-12

76. Page RDM, Lee PLM, Becher SA, Griffiths R, Clayton DH: A different tempo of mitochondrial DNA evolution in birds and their parasitic lice. $\mathrm{Mol}$ Phylogenet Evol 1998, 9:276-293.

77. Light JE, Hafner MS: Codivergence in heteromyid rodents (Rodentia: heteromyidae) and their sucking lice of the genus Fahrenholzia (Phthiraptera: anoplura). Syst Biol 2008, 57:449-465.

78. Kettle DS: Medical and Veterinary Entomology. 2 edition. CAB International, Cambridge; 1995.

79. Bueter C, Weckstein J, Johnson KP, Bates JM, Gordon CE: Comparative phylogenetic histories of two louse genera found on Catharus thrushes and other birds. J Parasitol 2009, 95:295-307.

80. Keirans JE: A review of the phoretic relationship between Mallophaga (Phthiraptera: Insecta) and Hippoboscidae (Diptera: Insecta). J Med Entomol 1975, 12:71-76

81. Johnson KP, Williams BL, Drown DM, Adams RJ, Clayton DH: The population genetics of host specificity: genetic differentiation in dove lice (Insecta: Phthiraptera). Mol Ecol 2002, 11:25-38.

82. Toon A, Hughes JM: Are lice good proxies for host history? A comparative analysis of the Australian magpie, Gymnorhina tibicen and two species of feather louse. Heredity 2008, 101:127-135.

83. Balakrishnan CN, Sorenson MD: Dispersal ecology versus host specialization as determinants of ectoparasite distribution in brood parasitic indigobirds and their estrildid finch hosts. Mol Ecol 2007 16:217-229.

84. Hopkins GHE: Stray notes on Mallophaga. - XI. 93. The identities of three forms described by Kellogg \& Kuwana. Ann Mag Nat Hist 1951, 12:375-377.

85. Grant PR, Grant BR: Conspecific versus heterospecific gene exchange between populations of Darwin's finches. Philos Trans R Soc Lond B Biol Sci 2010, 365:1065-1076.

86. Ortego J, Aparicio JM, Calabuig G, Cordero PJ: Risk of ectoparasitism and population genetic diversity in a wild lesser kestrel population. $\mathrm{Mol}$ ECO 2007, 16:3712-3720.

87. Kerr KCR, Stoeckle MY, Dove CJ, Weigt LA, Francis CM, Hebert PDN: Comprehensive DNA barcode coverage of North American birds. $\mathrm{Mo}$ Ecol Notes 2007, 7:535-543.

88. Folmer $\mathrm{O}$, Black M, Hoeh W, Lutz R, Vrijenhoek R: DNA primers for amplification of mitochondrial cytochrome c oxidase subunit I from diverse metazoan invertebrates. Mol Mar Biol Biotechnol 1994, 3:294-299.

89. Harpp KS, Wirth KR, Korich DJ: Northern Galapagos Province: Hotspotinduced, near-ridge volcanism at Genovesa Island. Geology 2002, 30:399-402.

doi:10.1186/1471-2148-11-284

Cite this article as: Štefka et al:: A hitchhikers guide to the Galápagos: co-phylogeography of Galápagos mockingbirds and their parasites. BMC Evolutionary Biology 2011 11:284 